This article was downloaded by: [North Carolina State University]

On: 10 March 2015, At: 05:29

Publisher: Taylor \& Francis

Informa Ltd Registered in England and Wales Registered Number: 1072954 Registered office: Mortimer House, 37-41 Mortimer Street, London W1T 3J H, UK

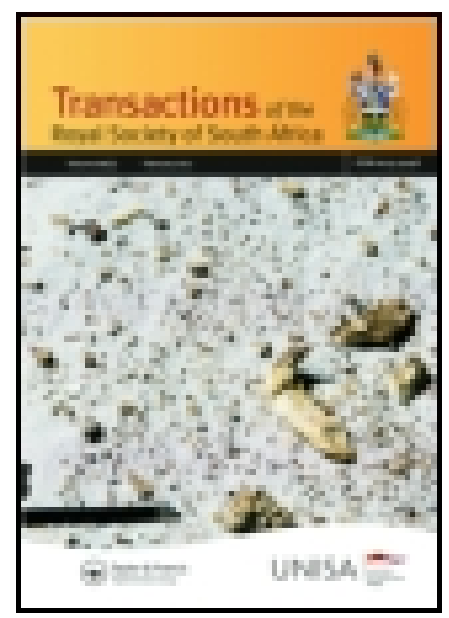

\title{
Transactions of the South African Philosophical Society
}

Publication details, including instructions for authors and subscription information:

http:// www. tandfonline.com/loi/ttrs19

\section{THE WINDS OF KIMBRELEY}

J. R. Sutton B.A., Cantab.

Published online: 28 J un 2010.

To cite this article: J. R. Sutton B. A., Cantab. (1900) THE WINDS OF KIMBRELEY, Transactions of the South African Philosophical Society, 11:1, 75-112, DOI: 10.1080/21560382. 1900.9525958

To link to this article: http:// dx.doi.org/ 10.1080/21560382.1900.9525958

\section{PLEASE SCROLL DOWN FOR ARTICLE}

Taylor \& Francis makes every effort to ensure the accuracy of all the information (the "Content") contained in the publications on our platform. However, Taylor \& Francis, our agents, and our licensors make no representations or warranties whatsoever as to the accuracy, completeness, or suitability for any purpose of the Content. Any opinions and views expressed in this publication are the opinions and views of the authors, and are not the views of or endorsed by Taylor \& Francis. The accuracy of the Content should not be relied upon and should be independently verified with primary sources of information. Taylor and Francis shall not be liable for any losses, actions, claims, proceedings, demands, costs, expenses, damages, and other liabilities whatsoever or howsoever caused arising directly or indirectly in connection with, in relation to or arising out of the use of the Content.

This article may be used for research, teaching, and private study purposes. Any substantial or systematic reproduction, redistribution, reselling, loan, sub-licensing, systematic supply, or distribution in any form to anyone is expressly forbidden. Terms \& Conditions of access and use can be found at http://www.tandfonline.com/page/termsand-conditions 


\title{
THF WINDS OF KIMBERLEY.
}

\author{
Bг J. R. Sutron, B.A., Cantab.
}

(Plates II-IX.)

\section{INTRODUCTION.}

Hourly observations of wind direction were commenced at Kenilworth (Kimberley) in February, 1896, and the object of the present paper is to attempt a preliminary sketch of the results obtained between that time and the end of February, 1899. It is true that as a general rule three years is all too short a period from which final conclusions can be drawn as to the true mean values of the principal meteorological elements. There are, hovever, weighty reasons for the course here adopted.

First, that continuous observations of the winds have not hitherto, so far as I know, been attempted at any place on the great South African platean; and indeed few of any importance in the whole country. This most unfortunate fact makes it almost imperative that a first approximation, at the least, to the position we occupy in the general wind-circulation of the globe should be made public as early as may be.

Secondly, that the vicinity of Kimberley is perhaps the site, par excellence, in the whole world upon which land winds can be most easily and advantageously studied in their physical relationships. In the majority of cases something more than the fitness of the site determines the position of a meteorological observatory. Considered, quite erroneously of course, as a science of minor importance, meteorology is as a rule attached in a subordinate capacity to the routine of institutions intended primarily for the study of astronomy, and so must be conducted in places chosen with reference not to its own requirements, but in accordance with those of a study differing absolutely from itself both in kind and in degree. Thus it comes to pass that the nearest approach to meteorological observations of the first class yet made in Sonth Africa have been those of the astronomical observatories of Cape Town and Durban. The qualifications of the 


\section{Transactions of the South African Philosophical Society.}

former may be dismissed in a very few words; saving for the study of local details its geographical position, meteorologically speaking, is the worst possible. A very much smaller mass than Table Mountain close by would be fatal to the general utility of its wind registers. Durban I have not seen, although from maps and descriptions it would appear to be as good a site as one could expect for a coast station, for all meteorological observations saving those of the winds. A perusal of the most excellent Annual Report of the Government Astronomer to the Colony of Natal establishes this very clearly. But I have attempted the construction of wind-roses from the data of the Natal Reports with most indifferent success. The drawback seems to be that Durban is screened almost completely from winds having a westerly component by hills at the back.

Granting that every place has both an annual and a diurnal wind circulation peculiar to itself, either or both may be obliterated or masked by perturbations set up in consequence of geographical conditions. Thus, on a coast, land- and sea-breezes may intervene; in the interior of continents mountain masses may deflect the wind currents and even reverse them altogether, or smaller perturbations may be introduced by the vicinity of lakes and large rivers. Kimberley possesses none of these drawbacks : it is very nearly on the central line of the continent; the land is gently undulating and little cultivated; there are neither large rivers nor lakes anywhere near, and neither hills nor mountains of any importance for hundreds of miles. It is to be expected, then, that the train of causes operating on the movements of the atmosphere over Kimberley should be the simplest conceivable, and that it would not be necessary (as in the case of India, for example) to make a number of more or less approximate assumptions as to the precise weight to be attached to numerous and widely varying perturbations, before laying bare such a train of causes in its rudimentary aspects.

Lastly, the Kenilworth observatory has no guarantee of permanent existence: it may come to an end at any time, and the chance never occur to me or to any one else of discussing the observations. Such a possible fate is to be deplored, but it has to be reckoned with, and for that reason this sketch has been attempted with what may be accounted a minimum of material.

\section{Instruments, Etc.}

Kenilworth is situated about three miles N.N.E. of Kimberley in approximate E. long. $24^{\circ} 40^{\prime}$, S. lat. $28^{\circ} 40^{\prime}$, at an altitude of some- 
thing less than 4,000 feet above sea-level. It lies on one of the gentle slopes characteristic of the undulating veld of Griqualand West, and is rather lower than the crest upon which the greater part of Kimberley is built. Though thickly wooded, the trees do not yet offer any impediment of importance to the free circulation of the air at a moderate height.

Observations of wind directions are derived from the automatic records of an Osler unemometer mounted with its vane about 36 feet above the ground. It has had a fair exposure hitherto, albeit this advantage is not likely to last very much longer unless it can be raised considerably higher. The friction of the various parts is considerable, though not greater, apparently, than that of other instruments of the same class. It is indeed less than that of a small, and very much lighter, vane mounted close by. Of the wind-pressure records from the same instrument little need be said, more especially since they are not used here. The motion of the vane is communicated by means of a rack and pinion to an aniline pencil beneath, which writes the directions continuously upon a moving band of paper controlled by clockwork. In the lighter winds of less than, say, five miles per hour the vane remains fairly steady approximately parallel to the direction, the pencil record being then a clear, if crooked, line; but with higher velocities the vane may swing rapidly and continuously as much as $40^{\circ}$ on either side of its mean position, making the pencil-record a broad shaded band. In the latter case the medial line of this band is taken as the true direction of the wind. The charts are changed every twenty-four hours, as punctually as possible at $10 \mathrm{p} . \mathrm{m}$. As originally constructed the instrument only allowed a transverse motion of the peneil equal to a range of $675^{\circ}$ for the vane, and in consequence the pencil was sometimes pushed out of gear, portions of the record being thereby lost. To guard against this, charts and pencil-rack were both altered to admit a range of $1260^{\circ}$ in the vane, with satisfactory results. In general the portions of the record lost as above were interpolated in either of two ways, according as the vane carried the pencil gradually and slowly, or by one swing across the chart out of gear. In the former case it was assumed that the changes were also gradual for the hours of lost record; in the latter case that the vane had swung at once to the point at which it stood when the accident was discovered.

Observations of wind velocity are derived from the records of a Robinson anemometer of the standard Kew pattern, mounted on a post at a height of 40 feet. At first the velocity was only registered on dials, no hourly record being taken. In March, 1897, however, Mr. Henderson, of the De Beers Clushing Mill, constructed a count- 
ing apparatus for me by means of which an automatic record could be written with a pen upon a Richard drum. This very ingenious contrivance admits of a wide range of speed multiplication; as used, and found most convenient, the pen rises once for each two and a half miles of wind, falling to zero and rising again, and so on. It has worked uniformly well, the only break in the records occurring for a few hours when a screw of the shaft comnecting the cups with the dials had worked loose. Until the repairs were completed the velocities were interpolated from as many interim readings as could be made. The charts can run for twenty-four hours, but for a portion of the time the pen would be running over the brass strap binding the chart to the drum. For some considerable time the charts were changed at the same hour as the Osler charts, the mileage to be added for the time during which the pen was on the brass strap being taken from the readings of the dials. This was found, however, to give not quite correct values, and latterly, in consequence, the charts are changed an hour or so earlier each day, eight being used in a week. A small correction is sometimes necessary to the registered hourly velocities because the hour-lines are not quite truly centred. There seems to be very little friction in this instrument.

The barometric records are taken with a Beckley Photo-barograph (by Messrs. Negretti and Zambra), the ordinates being converted into true hourly air-pressures by comparison with three readings per diem of a large station standard mercurial barometer.

The temperatures of the air and of evaporation are read directly from the hourly registrations of a set of Negretti and Zambra's reversing thermometers, supplemented in a subordinate capacity by the indications of a Thermograph and a Hygrograph, both by MM. Richard, of Paris.*

\section{Wind DiRection.}

The first circumstance to be investigated is the relative frequency of the winds, referred to the sixteen principal directions, for each month and for each hour. For this purpose the mean direction of the wind during' each whole hour was determined as nearly as possible, and entered in its proper column in the summary. Only those hours are excluded in which the vacillation of the vane made

* For a fuller description of the various instruments see the introduction to the Kenilworth observations, published, by permission of the directors of the De Beers Consolidated Mines, Ltd., in the annual report of the Meteorological Commission of the Cape Colony for 1898. The site is not a very good one for temperature observations. 
this mere guesswork. Calms, which are comparatively rare, are included equally with the others. Some difficulty was experienced in assigning the direction in those cases where the mean hourly direction fell very nearly between two of the sixteen directions, and there seems to be no doubt that a certain amount of bias displayed itself from time to time favouring some of the points in question at the expense of those adjacent. It might be expected that such a bias, not being deliberate, would rectify itself in time, but the gradual accumulation of the numbers to the final totals did not completely bear out the expectation. At the same time it may be claimed that no error large enough to materially alter the true monthly or hourly resultants was introduced in this way.

Table 1 gives the number of hours of wind, irrespective of velocity, for each of the sixteen principal compass points during each month from the three years' observations. Fig. 1 is a graphical representation of what may be called the resultant wind-direction calculated for each month, and for the whole year, from the numbers of Table 1. It is formed by drawing rectangular axes NOS, EOW, through the origin $\mathrm{O}$, and projecting the number of hours of each wind upon them. Thus each direction multiplied by its numerical coefficient will have two components, one upon the axis NOS, and the other upon EOW. All components falling along EOW in the direction $\mathrm{OE}$ are conventionally plus, and all in the direction $\mathrm{OW}$ minus. Also $O N$ and $O S$ are in the same way conventionally plus or minus respectively. The final resultant is formed from the components by the principles of the parallelogram of velocities. Consider, for example, the wind numbers for January, and let $\mathrm{N}, \mathrm{E}, \mathrm{S}, \mathrm{W}$, represent the respective components measured along $\mathrm{ON}, \mathrm{OE}, \mathrm{OS}, \mathrm{OW}$; $\mathrm{R}$ being the final resultant. Then we have-

$$
\begin{gathered}
\mathrm{N}=185+(227+144) \cos 221_{2}^{\circ}+(149+161) \sin 45^{\circ}+(107+195) \sin 221^{\circ} \\
\mathrm{E}=97+(195+130) \cos 222^{\circ}+(161+93) \sin 45^{\circ}+(144+110) \sin 222^{\circ} \\
\mathrm{S}=105+(173+110) \cos 222_{2}^{\circ}+(141+93) \sin 45^{\circ}+(139+130) \sin 222_{2}^{\circ} \\
\mathrm{W}=59+(107+138) \cos 222^{\circ}+(149+141) \sin 45^{\circ}+(227+173) \sin 222^{\circ} \\
\quad \therefore \mathrm{N}-\mathrm{S}=228 \cdot 1 \\
\mathrm{E}-\mathrm{W}=30 \cdot 6 \\
\text { Whence } \mathrm{R}=\sqrt{ }\left((228 \cdot 1)^{2}+(30 \cdot 6)^{2}\right\}=230 \cdot 14 \\
\text { And } \tan \theta=
\end{gathered}
$$

The components for each month found in this way are given in Table 2. But it must be noted that neither the components, nor their resultants, of themselves are to be interpreted as necessarily 
revealing the prevailing directions of the wind. Such a conclusion can only be drawn when the tabular numbers from which they are derived show also a distinct and overwhelming majority for one direction over each of the others. Should there be, say, two directions, each containing preponderating numbers, then the resultant will lie between them, and may (almost certainly will, in the case of valley winds, or of land-and sea-breezes) lie along a direction from which relatively few of the winds come. Referring again to Table 1, it will be seen that although certain directions do prevail at the expense of the others month by month in a moderate degree, yet any preponderance for the whole year is comparatively insignificant. Month by month, then, we may take it as a rule that the prevailing direction is approximately that of the resultant, and such that (see Fig. 1) it blows from the denomination of the month to the origin of the figure with a frequency and proximity proportional to the space described, whereas for the year it is not so.

Table 3 gives Table 1 in a condensed form, the wind numbers being arranged in quadrants. It both smooths and emphasises the monthly variations of Table 1. Apparently, however, Table 4, in which the numbers of Table 1 are arranged in periods of four months - a condensation suggested by Fig. 1-is mole advantageous. From this we conclude that the prevailing directions are north-northwesterly from January to April, easterly from May to August, south-westerly from September to December. Fig. 2 is a graphical representation of this feature, and Table 5 the components. It appears to be extremely likely that if sufficient observations can be taken it will be found that the wind in the course of the year backs with uniform angular velocity clockwise round the compass.

Of the 25,898 hours of wind analysed throughout the three years the final resultant contains the small components of only 50 hours to the north, and 100 hour's to the west, being exceeded in magnitude by those of every separate month with the exception of July. The resultant of each of the three years, also, is much greater than that of the final resultant of the three together; moreover, neither bears the least resemblance to either of the others. They are :-

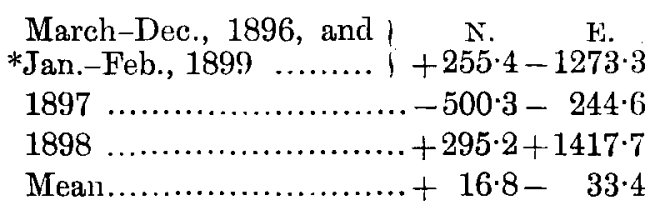

* January and February, 1899, are added, to complete a year, to the ten months March-December, 1896, and so as to avoid breaking up the full years 1897, 1898. 
The total lack of resemblance between these four pairs of components is further illustrated in Table 6, in which the hourly wind frequency for each year is shown separately. It may be observed that an extra week of anticyclone weather would have been sufficient to transfer the final resultant of the combined three years bodily into the opposite quadrant.

There is apparently no escape from the conclusion that while sometimes one and sometimes another direction may preponderate from year to year, there is nothing to definitely establish the existence of a prevailing wind at Kimberley. On the face of it there is nothing remarkable in this fact, if it only be remembered that the place is in the great southern anticyclone belt, midway between the trades and the brave west winds of the southern ocean. Apart from that it is completely at variance not only with the popular idea, but also with every account touching upon the subject (the Challenger Report included) yet published. Universal opinion for many years past has assigned us an overwhelming excess of northerly winds, some extreme views asserting there is nothing else. Theories even have been propounded explaining why the wind is so very northerly: wherein we learn that the trades being deflected from the ocean by the excessive heat of the African interior curve round and run southward along the centre of the southern table-land, for want, it seems, of elsewhere to go! Fortunately we shall be in a position later on to see how it is that the idea of a prevailing north wind arose, and why it has no foundation in fact.

Assuming then that no prevailing direction exists, we may proceed to investigate the salient features of the winds of Kimberley as a local phenomonon unperturbed by outside influences. We will consider first whether the diurnal changes are more clearly defined than the annual. Table 7 shows at once that they are. Evidently the tendency of each wind is to blow with its maximum frequency an hour or two later than the wind tabled next it, and the consequent inference must be that the undisturbed vane makes one complete, counter-clockwise rotation per diem. There is a slight departure from, and exaggeration of, the rule in the case of east and east-southeast winds, but the directions on each side fall into line precisely as if the maxima were perfectly regular throughout. Furthermore, perceptible, though relatively unimportant, maxima do occur in both these directions near the required times. Standing out very clearly is the lack of southerly winds during the morning, and of northerly winds during the evening, --the almost entire absence of easterly winds by day and of westerly winds by night. With the object of making the daily changes clearer, and of eliminating the influence of the 
irregularities in the totals at the foot of the columns, each number has been reduced to proportional parts of a thousand in Table 8 . Here we elicit the remarkable fact, to be further touched upon when the velocities come to be considered, that the highest percentages at the times of maximum frequency occur in the case of those winds whose maxima are at, or near, noon. Indeed only these run into three figures. It is partly a result of this that the lowest percentages at the times of minimum frequency occur at midday to those winds whose maxima are at or near midnight. There is, however, a considerable contrast between the curves for the two classes: the former having a long-drawn-out minimum with a rapid rise to and fall from maximum; the latter an equally long-drawn-out maximum with a rapid fall to and rise from minimum.

The hourly components of wind-frequency are shown in Table 9. They are calculated from Table 7 in the same way as Table 2 is calculated from Table 1. Their interpretation may be best illustrated by an example: For the hour ending at noon the components in Table 9 are $: \mathrm{N}=+344 \cdot 2 ; \mathrm{E}=-378 \cdot 1$. This means that for that hour during three years the northerly components exceeded the southerly by $344 \cdot 2$ hours, and the westerly exceeded the easterly by $378 \cdot 1$ hours. The results are shown graphically in Figs. 3 and 4 .

In Fig. 3 the heavy line is the north component curve; the other is the east component curve. The portions of both curves are conventionally positive above the zero line (upon which the hours are marked), and negative below. Thus for all portions of the curves above the line the directions prevailing are northerly and easterly, but southerly and westerly for all portions below. We see, according to the figure, that the east component reaches its greatest positive and negative excursion at the respective hours ending $6 \mathrm{a.m}$. and 3 p.m. - say at mean times 5.30 a.m, and 2.30 p.m.- these hours, as it happens, being the times of the mean minimum and maximum temperatures of the day. In other words, the vane is swinging from east to west with a rising temperature, and vice versd. The dotted line in the figure is the diurnal temperature variation inverted. That is, it represents the consecutive hourly values of $M-t$ where $M$ is the mean daily temperature, and t the temperature at any hour. By suitably choosing the scales of hours and degrees, the curves can be made to look very much alike. That the east and west swing of the vane is a direct effect of the temperature is scarcely to be doubted. The barometric curve (see Table 12 and Fig. 7) follows the east component curve by some two hours so far as the portion included in the daylight hours is concerned, but the night maximum of the former has no corresponding feature on the other. The north com- 
ponent curve, on the other hand, passes through its maximum and minimum points shortly after the two hours of mean temperature; but apart from this there is no obvious connection between it and either the temperature or the pressure curve. The long-drawn-out maximum of the winds prevailing at night, and the shorter but sharper maximum of the day winds, previously alluded to, here receive at least a partial explanation from the fact that the diurnal temperature is below its mean value for a longer period than it is above.

Fig. 4 displays in one curve, and on the same scale, the resultants of the component curves of Fig. 3. In this figure northerly components are measured vertically upwards or downwards, according as they are positive or negative, easterly components being measured horizontally to the right or left in the same way. The resultant wind for any hour is supposed to be moving inwards from the number denoting the hour to the origin of the co-ordinates. Thus, during the hour ending 9 a.m. the mean resultant direction of motion is almost due south, i.e., the resultant wind is northerly. The curve is very nearly an ellipse, having its major axis on the line joining the hours ending at noon and midnight. It is a curious and possibly significant fact that if the times of maximum, minimum, and mean temperature be marked upon the curve, the line joining the times of maximum and minimum will intersect the line joining the times of mean temperature almost at the origin.*

The angular velocity of the resultant varies considerably, being greatest for an hour or two after sunrise, and for about the same interval after sunset. For each quarter of a day the mean angle described is approximately-

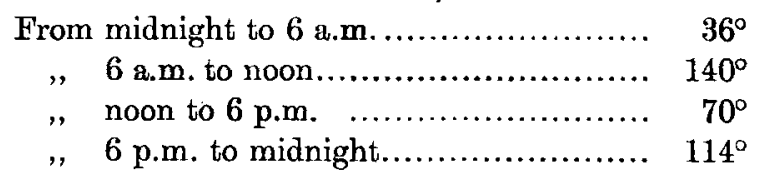

the east and west vibration showing itself by far the more influential. This point may be investigated in a rougher, if not less interesting way by tabulating the mean actual movement of the vane direct from the automatic registers for each quarter of a day. The method followed here was to consider the exact points (as nearly as they could be ascertained) at which the pencil crossed the respective

* To prevent confusion, these lines are not drawn. Should the reader wish to insert them, it must be remembered that the horary numbers marked round the curve stand for the hour ending at the time indicated. Thus, 8.30 a.m., for example, should be taken as the mean tine of the point IX. 


\section{Transactions of the South African Philosophical Socioty.}

hour-lines of midnight, 6 a.m., noon, and 6 p.m. as the points of departure and arrival, the total angular deviation of the pencil in each interval being entered in its proper column. The results showing the mean movement for each day, and each quarter of a day, during each month, are shown in Table 10. If it be distinctly borne in mind that an instantaneous reading of wind direction cannot be trusted to give information equally trustworthy with that of a mean hourly reading, the agreement between Table 10 and the more formal values of Table 9 will be sufficiently satisfactory. It is evident that the angular velocity of the vane is much greater in summer than in winter, the diurnal mean for the year being rather less than one-third that of the sun. The remaining two-thirds, due to perturbationse.g., storms - and partly no doubt to instrumental faults, have no appreciable effect upon the velocity of the resultant, althongh they must considerably reduce its length throughout the day. Instances in which the vane travels backwards are probably more common after noon than before. They seem to occur either when the vane has advanced more rapidly than usual for a few hours previously, or when, upon the dying away of some disturbance deflecting the air current, the vane takes the shortest cut to its normal position. That there is not, however, any material difference between summer and winter in the diurnal frequency-curves of the different wind directions is demonstrated by Table 11, in which the numbers are ratios per thousand arranged in quadrants; the months of December and January for three years providing the summer values, June and July the winter. The greatest differences are in Quadrant 4 (including all winds from west, west-north-west, north-west, and north-north-west) the summer curve here being appreciably flatter. Any other months give just the same sort of information. Perturbations are seldom of long duration, the longest "set-in" wind on record not perhaps lasting three days; and even when they occur their effect is confined almost exclusively to the addition of a practically constant number to each hour for the set-in direction. Whence it is that the frequency-curves retain their shape unaltered.

\section{Wrid Velocities.}

Hitherto we have dealt only with the simple directions of the wind irrespective of the corresponding velocities. It is usually the custom to discuss the two together, ignoring the directions as a separate factor, especially in dealing with the rectangular components, although it is not easy to see why. Table 12 will demonstrate that there is some advantage in making a distinction between the two. It is constructed from two years' observation of velocity 
and direction together-for, as we have seen, hourly observations of velocity were not commenced until March, 1897. There are seventeen columns:-

1. The hours of the day.

2. The mean hourly velocity.

$3,4,5,6$. The mean hourly velocity for each quadrant of directions. $7,8,9,10$. The hourly departure, $Q_{n}-M$, from the mean velocity $M$ of the same hour (where $Q$ is a quadrant and $n$ its number) smoothed in threes by Bloxam's process.

$11,12,13,14$. Numbers such as those of Table 7 , but for two years instead of three, also arranged in quadrants.

15. The hourly values of the humidity of the air for the year 1898.

16. The mean hourly rate of evaporation from a free water surface.

17. The hourly values of the mean barometric pressure of the air.

It is to be understood, of course, that every particular value in the table is, with the exception of those in the humidity and pressure columns, for the hour ending at the time indicated on the same row by the first column. In the humidity and pressure columns the values apply to the hour.

The diurnal curve of wind velocity contains two maxima (at 2 p.m. and 10.45 p.m.), * and two minima (at 5 a.m. and 7.30 p.m.). The second maximum is of more than ordinary interest. It is strongly marked in the winds of the second and third quadrants, but is not so conspicuous in those of the first and fourth. In the diurnal curve of evaporation from a free water surface there are also, as it happens, two maxima in the hourly rates falling at the same hours as those of the wind velocity. The first is obviously due to the high wind velocity and low humidity during the warm hours of the day. Now the humidity curve rises rapidly, particularly during the winter months, from just before sunset until about 8.30 p.m., after which, for three hours or so, the rate of increase is not large. The second maximum in the rate of evaporation is not, therefore, difficult to understand. This matter, however, is merely mentioned in passing.

Columns 11-14 give essentially the same rule as Table 7. But the chief interest of Table 12 is to be looked for in columns 7-10. The numbers they contain are in remarkably regular sequence, and would doubtless be even more so in a more extended series. They discover in a most decided fashion the important fact that for any hour of the day the mean velocity of the wind from any quarter decreases relatively to mean diurnal curve, with the deviation of the

\footnotetext{
- The actual value of the second maximum is only approximate in consequence of the uncertainty introduced by the obstruction to the record of the brass strap between the hours XXI. and XXII.
} 
vane from its normal position. The inference seems to be that over and above instrumental faults which may contribute something to the result, storms, and other disturbances occurring here, are, on the whole, little else than exaggerations of normal conditions. The curves illustrating columns 7-10 are shown in Fig. 5 .

The fact will now be readily appreciated that because the winds which prevail during the middle of the day come from between north-east and north-west, and also because the velocities are greater when the directions are normal, these, if only through the dust they raise, will attract the most attention from the " man in the street," who as a rule only notices what is forced upon him. The published accounts owe their inspiration in the main to the observations taken for the Meteorological Commission of the Cape Colony by amateur observers. Now the hour of observation is 8 or 9 a.m., and a glance at Table 7 will be sufficient to prove that either of those hours will return a great preponderance of winds lying between north and north-east. Thus we see how it comes about that both scientific and unscientific observation have independently evolved the same totally incorrect conclusion.:

The number of miles of wind recorded from each direction, irrespective of the duration, for each hour during two years is given in Table 13. It will be seen that the highest values occur about midday - as might be expected from Table 12-and that on the whole the columns containing the highest numbers also contain the lowest. The components of Table 14 are calculated from Table 13 exactly as those of Table 9 from Table 7 . Fig. 6 is a graphical representation of the results of Table 14. So far as its critical points are concerned it is substantially a reproduction of Fig. 3, each component possessing only one pair of simple maximum and minimum points, temperature affinities being equally apparent in the east component curve, and barometric affinities, so it seems, equally lacking in both curves.

By dividing the directions into quadrants we get the following total mileages in two years:-

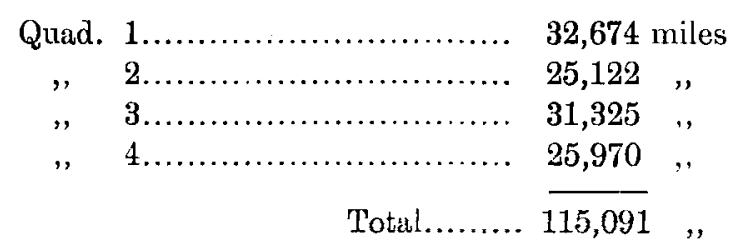

* Dr. Buchan gives the following yearly totals for Kimberley derived from observations made at 8 a.m. and 8 p.m.: N., 87 ; N.E., 72 ; E., 57 ; S.E., 15; S., 51 ; S.W., 24 ; W., 28; N.W., 20.

The inference would be a prevalence of northerly winds. The observations are evidently quite homest, but they are insufficient. 
These numbers show, even more convincingly than Table 14, how small is the total unbalanced excess of air passing over Kimberley. Small even as it is, only amounting to about five miles per day on an average throughout the two years, it would no doubt have been very much less in the three years comprised in the investigation of directions.

At this stage we may look at Figs. 3 and 6 in a different light: we may assume the former to represent $\Omega$ system in which the air is moving with any constant velocity; the latter as a system formed from the second by the intrusion of air-currents of variable strength from whatever cause arising. Table 15 is constructed from Tables 9 and 14 for the purpose of comparing the effects. Here column 1 contains the hours, columns 2 and 5 the mean hourly component movements for a year, columns 3 and 6 the mean relative component frequencies-or, which comes to the same thing, the mean movement at a constant velocity of 6.6 miles per hour,-columns 4 and 7 are the departures of the variable velocities observed from the constant velocities assumed, column 8 is the resultant departure, being equal to the square root of the sum of the squares of corresponding numbers in columns 4 and 7 (decimal places being omitted throughout). The actual magnitudes of the numbers, regardless of sign, in columns 2 and 5 , are in almost all cases greater than those of columns 3 and 6 , as might be expected from the fact mentioned in reference to the values of columns $7-10$ of Table $12 . *$

Fig. 7 gives a graphical representation of the values $\mathrm{V}-\mathrm{C}, v-c$, found in Table 15, the curve of barometric variation being also inserted. Some of the minor irregularities might possibly disappear in a greater number of years of observation. But as it stands it places the north component rariation in as uninfluential a position as the north components of frequency and movement. The east component curve, on the contrary, is of remarkable interest. If its asperities be not smoothed by future research, then it undoubtedly contains three pairs of maxima and minima. The three maxima precede by respectively lengthening intervals, the first (lesser) barometric minimum, and the two barometric maxima, the most pronounced minimum of the east component variation being also in advance of the most pronounced barometric minimum; whereas the north component variation seems to follow, with a curious exception at 8 p.m., the diurnal pressure tides. Now we have seen that the east and west swing of the vane coincides with the variations of tem-

\footnotetext{
- Recollect that the component frequencies are dorived from the registers of three years, the component movements from only two. For the purposes of this comparison the former are accounted standard forms for any year.
} 
perature. Judging by the diagram is it not highly probable that the secret underlying the double diurnal oscillation of the barometer is to be looked for behind the complicated variations introduced as east components of wind-frequency and air-movement by the simple application of the sun's heat? At any rate this aspect of the problem is worth further inquiry.* The greatest excess variation from the east is followed by the greatest excess variation from the west; and, as it were, in response, the barometer also executes its greatest vibration. If it be not cause and effect, the coincidence is remarkable. However this may be, the diurnal northing and southing of the air, at any rate, both in duration and amount, is quite a secondary effect, indicating no more, perhaps, than an attempt to restore the equilibrium disturbed by the east and west exchanges.

From Tables 7 and 8 it is evident that the normal wind of Kim. berley moves inwards, at any time, from a moving radiant always situated some $30^{\circ}$ or $40^{\circ}$ in front of the point where a vertical circle through the sun cuts the horizon; the only departure being, as already noted, in the case of easterly winds, which, so far as the observations go, have one maximum somewhat earlier, and thus contribute to the third maximum of the east component variation. These consecutive directions may all be included in the scheme of Fig. 8, wherein each instantaneous direction is tangential to a spiral circling outwards from the area of highest temperature and inwards to the lowest. The simplest conception of the diagram is to imagine it, together with the hour numbers, an appendage of the sun encasing the earth (which rotates inside it), $\mathbf{S}$ and $\mathbf{S}^{\prime}$ overlapping. $H$ is the area of greatest heat nearly facing the sun, $C$ that of greatest cold, $\mathrm{KK}^{\prime}$ the path described by Kimberley through the system with a velocity approaching 1,000 miles per hour. The arrow-heads show the direction of wind motion.

The hypothesis demands that the diurnal wind system shall be an anti-convection current; but since the text-books frequently state that wind must blow from cold to warm areas this seems at first sight an impossibility. While it is easy to draw a similar spiral of opposite curvature which shall equally represent the hourly motions, and yet shall be, in a sense, a convection current, the one mechanical consideration fatal to such a construction is that a current running in to $H$, say from the south ( $H$ being south of the equator), must first curve to the left, and then gyrate clockwise round $H$. Now it is quite certain that if the sun could remain vertically over one spot true convection currents must eventually be established, but it is not

* See, however, Mr. H. F. Blanford's paper "On the Winds of Calcutta" in the Indian Meteorological Menoirs, vol. i. p. 18. 
necessarily so under existing conditions. For consider what goes on in the vicinity of the sub-solar point. The air here near the ground is being heated with great rapidity and is expanding in all directions outwards and upwards. Before the process, however, has gone sufficiently far to allow the lower air to expand enough to set up an outflow overhead and a convection current below, the sub-solar point has shifted to the west, the motive power is on the decline, and hence only the beginnings of the establishment of convection currents are ever manifested. The pushing-out process may be expected to make itself felt right up to the borders of the great circle of which $\mathrm{H}$ is the pole; and it is worthy of note that the greater maximum of the barometric tide shows itself on the western edge of the same circle, the lesser maximum falling some $30^{\circ}$ behind the eastern edge. Throughout the space containing $H$, lying between these two tidal crests, the wind variations are in perfectly regular sequence.

In the cold hemisphere we have, to start with, an opposite state of things. At the cold spot $C$ the air is contracting inwards and downwards, but with far less intensity than the expansion near $\mathrm{H}$. By first intention, then, the expanded air will tend to move into the cold hemisphere. The contraction increases the pressure at the cold spot, being aided, perhaps, by the greater barometric crest lying some $45^{\circ}$ away. The greatest effect of the contraction will therefore make itself felt not at $\mathbf{C}$, and still less towards $\mathbf{S}^{\prime}$, but further to the west. In sympathy with this the lesser crest which might have remained on the border of the warm hemisphere moves eastward until the gradients on each side of the lesser minimum are equalised. It must not be thought that I ain trying to manufacture a satisfactory explanation of the cause of the barometric tides; the important fact to be insisted upon is that the circulation inaugurated about $\mathrm{H}$ is developed well into the cold hemisphere by the asymmetry of the barometric maxima and by the contraction in front of $\mathrm{C}$. Once there the directions will shift normally as in a clockwise circulation in consequence of the tendency to an indraught about the depleted space. The deflecting force is no doubt small, but on the other hand the winds are light, and hence the more easily turned. With stronger currents the right-handed gyration about $\mathrm{C}$ would be much less pronounced-always supposing the motion imparted from the outside-and this it seems explains why, when at 11 p.m. the wind velocity attains its second maximum, the wind directions tend to fly off centrifugally from the right-handed gyration. The straight arrow in the figure is an attempt to represent this. It stands for the intrusion of the abnormal maximum frequency of easterly winds about 11 p.m. The actual depletion to the west of $\mathrm{C}$ will depend more 
upon the rate of fall of temperature than upon its actual degree. The space over which it extends will be much larger and much less clearly defined than the corresponding space about $H$, the windfrequency maxima being less pronounced accordingly.

It must not be imagined for a moment that Fig. 8 represents the path of any particle of air. Such an idea would imply velocities of upwards of a thousand miles an hour, which are, fortunately, out of the question. We are simply asked to understand that as Kimberley describes its diurnal rotation, its mobile air covering takes up successively the directions of motion of those portions of the imaginary vortex-system through which it may be passing. Each particle will tend to describe a spiral it is true, but in no individual case will the actual path accurately resemble that of the diagram, although the mean path of all the particles may do so in general shape.

It seems to follow that the diurnal wind system of Kimberley must be exceedingly shallow, not extending many thousand feet above the earth's surface, and this is supported by the motion of the clouds which, with few exceptions, travel along paths radiating from somewhere between north and west, irrespective of the wind directions below.

If the wind system of Fig. 8 is a correct interpretation of the Kimberley winds, it must be of universal application; and should, when allowances have been made for latitude (north or south), for prevailing winds, land-and sea-breezes, \&c., apply to every place lying within $45^{\circ}$ of the equator, if not beyond. The winds of Adelaide certainly seem to come within its scope, and possibly also those of Cordoba, although these latter have not yet been fully tested.* Meanwhile it may not be out of place to remark that a strong prevailing wind blowing, say, from the north, would increase the northerly winds both in frequency and strength, deflecting the east and west winds to the south, and probably cut off $\cdot$ southerly winds altogether.

\section{Wind-Roses.}

The remainder of this inquiry deals superficially with the variations in the four elements of barometric pressure, air temperature,

\footnotetext{
* Cordoba lies in the deep valley of the Rio Primero. A few miles to the west are some considerable ranges of hills, and 300 miles further are the mammoth peaks of the Andes. See "Frequencia Relativa Media Annual de los Vientos" in the Anales de la Oficina Meteorólogica Argentina, vol. ix. p. 353. Few nations equal Argentina either in the quality of its meteorological observations, or in the sumptuous volumes in which they are published.
} 
moisture, and cloud, corresponding to the various deviations from the normal wind directions. The first three of these are for the hours 2 and 8 (a.m. and p.m.), but there are no obserrations of cloud at 2 a.m. In the present section the instantaneous wind directions at the hours named are used.

1. Pressure.-The method of reduction first attempted was the very simple one of adding together every pressure under assigned wind directions, and taking the mean for the whole three years. The resulting curves, however, were extremely irregular. The reason was not at first obvious, but a second examination of the work showed that certain directions happened to prevail say in a winter month with its customary high mean pressures, and other directions, say in a summer month with its customary low mean. To avoid this element of confusion, the process was adopted of drawing separate curves for each of the four hours of every month, and then reducing each curve by the simple addition or subtraction of a number, constant for that particular curve, to the mean pressure of the three years, the assumption being made, and supported to some extent by the monthly results, that each monthly curve resembled every other in shipe. In this manner the effect of a greater or less number of directions from any assigned compass-point was eliminated. Finally the results were "bloxamed" in sets of three. Table 16 gives both smoothed and unsmoothed values.

The mean pressures of the day have a primary maximum with winds from the south-east, and a secondary maximum with those from the north-west; a primary minimum with winds from the west-south-west, and a secondary minimum with those from the north-north-west. There appears to be, as well, a tendency for the wind accompanying the highest pressure to radiate from a point which vibrates to and fro along a small arc of the horizon in the course of the day.

2. Temperaturik.-Table 17 gives the temperature results calculated in the same way as the last. The mean temperatures exhibit one maximum with winds slightly to the north of north-north-west, and one minimum nearly south-south-east. But while the minimum temperature seems to accompany the wind of sreatest air-pressure, the maximum travels with the sum (see the smoothed values), through pretty well a light angle. If future inquiry prove this to be a general law the passage of the warm point back to the north-northeast between 8 p.m. and 2 a.m. must be very rapid, and its hourly rate well worth study.

3. Dew-point's.--The dampest point is nearly midway between north-east and north-north-east, the driest point being exactly 
opposite.* Both have a tendency to shift against the sun before noon and with the sun afterwards. It is curious that there is a wider range in the amount of moisture carried by the winds at night than there is by day. The reverse holds with the temperatures, in which the greatest ranges are by day, following in this respect the same law as the pressures.

If a line be drawn N.N.E.-S.S.W., all winds from the east side come with an average pressure above the mean, and all from the west with an average pressure below. This has a further bearing on the facts revealed in Fig. 7. The mean temperature line is nearly E.-W., and the line of mean dew-points E.S.E.-W.N.W.

4. Croun.-Only the cloudiness of the sky with reference to particular winds is here considered, no account being taken of the sort of cloud. Table 19 gives the average amount of cloud accompanying each wind at 8 a.m., 2 p.m., and 8 p.m., together with the mean of the three hours; also smoothed values of each with their smoothed mean, which last, plotted to scale, might be called the normal curve. The last three lines give the departures from the normal. Northerly winds are accompanied by the most cloud, and southerly winds by the least. This feature is contributed to in two ways : frrstly, because in the diurnal range the cloudiness is greater at $2 \mathrm{p} . \mathrm{m}$. (when northerly winds are prevalent) than at 8 a.m. or 8 p.m.; and secondly, because the ruling directions of cloud motion have a very large northerly component. The set-in south-easterly winds, when they occur, moreover, we in the main anticyclonic, with elear skies. But over and above this we have the most significant result that, relatively to the normal curve, the clondiness of the sky increases with the deviation of the vane from its normal position.

In conclusion, it should be said that the whole of the material of this paper has been worked up in spare time, and chiefly by lamplight; so that, while every effort has been made to ensure accuracy, if a few numerical errors have crept in, it is no more perhaps than might be expected. Some eminent professional meteorologist in the future will, I trust, be able to make a fuller discussion of the winds of Kimberley, and with a lighter handicap. The wind-roses alone will repay the most elaborate treatment, and particularly, I believe,

* The behaviour of the dew-point at 6 p.m. is very anomalous. The prevailing winds at this time are south-westerly, which, for the hours included in Table 18, are shown to be the driest. But the dew-point curve attains its second maximum about 6 p.m.! It would seem, then, that the law of Table 18 does not apply to the sunset hours. Certainly the circumstance calls aloud for investigution. I hope to discuss this, together with some other points of interest not included here, later on. It is somewhat of a mystely where the increase of moisture at sunset comes from. 
for the hours of $6 \mathrm{p} . \mathrm{m}$. and $11 \mathrm{p} . \mathrm{m}$. In view of the fact that time has prevented the inclusion of these in this general sketch, all minor, even if important, details have had, a fortiori, to be severely left alone.

\section{APPENDIX.}

The general outline of this paper was complete before I had the good fortune to consult a remarkable paper by Mr. F. Chambers "On the Diurnal Variations of the Wind and Barometric Pressure at Bombay." * Much of the argument therein contained seems to want further proof; but there is no doubt that the plea for anticonvection currents is most ably maintained. As opposed to this we have the theoretical opinions of W. von Siemens some seventeen years later.t The latter compares the atmosphere to a number of adjacent chimneys in which heated air rises with great rapidity, and although these are described as having elastic walls, yet in no place, apparently, has this property been brought into requisition. For "disturbances are balanced by means of ascending currents," and, moreover, "if the heating of the lower strata of air takes place within a limited area, a local outflow" [upflow seems to be meant] "occurs, reaching to the uppermost regions of the air." While there is no difficulty at all in understanding that the heated air of the whole torrid zone must rise and flow off polewards, even if observation had not confirmed it, it does not seem so clear that the same result must follow from local and limited heating. Observational confirmation, at any rate, is quite wanting. Still less is there any solid foundation for the further statement that "the maximum and minimum air-pressures are effects of the temperature and velocity of currents of air in the higher strata of the atmosphere." It is much more antecedently probable that the latter will be eventually explained by the principles of the Wave Theory than by causes so remote and changeable. H However that may be, it is quite certain

* Philosophical Transactions, vol. 163, pp. 1-18. Read before the Royal Society, June 19, 1873. See also Procectings of the Royal Socicty, vol. xxv. pp. $402-411$.

+ "On the General System of Winds on the Earth." Phil. Mag., Dec., 1890.

†Vide "On the Vibrations of an Atmosphere Periodically Heated," by Max. Margules, translated from the Sitzungsberichti der König. Akad. der Wissensch. zu Wien, 1890; in Prof. Cleveland Abbe's Mcchanics of the Earth's Atmospherc. Also a paper by Lord Rayleigh, translated (from Euglish into Amorican) from the Phil: Mag., Feb., 1890, in the same volume: 


\section{Transactions of the Sonth African Philosophical Societ?.}

that, if the chimneys are to stand, the diurnal changes of wind-direction cannot be due to an outflow beneath of air from a heated region and inflow to a cold. The following simple calculation (which may or may not be new) has some bearing on the problem:-

Suppose the climatic and geographical conditions peculiar to Kimberley to prevail for the same latitude in a narrow zone completely round the world; that is, let the temperatures and pressures throughout have the same maxima and minima and the same daily variations. At any instant mark the twenty-four points at which the times are whole hours, and on each point imagine a cube of air, whose volume at $32^{\circ} \mathrm{F}$. is 1,000 (in any small units), to be situated. By virtue of the expansions - supposed equal in all directions-due to the mean temperature at each point for the hour, the cubes will have expanded from the volumes at $32^{\circ} \mathrm{F}$. to the volumes shown by column 2 in Table 20. For all temperatures below the mean these volumes may be regarded as contractions from the mean volume at mean temperature, and for all temperatures above the mean as corresponding expansions. Suppose the temperature and pressure to change, hour by hour, per saltum, so that, for $7 \frac{1}{2}$ degrees of arc on each side of the hour points, the temperatures and pressures are the same as that at the hours. Also let $u$ of the cubes, at mean temperature, placed end to end, occupy each of the areas whose centre is at any hour. Column 3 shows the length of each base for the times indicated in column 1 , column 4 the departure from the mean length, column 5 the base areas, and column 6 the departure from the mean area.

Now, taking only statical conditions into account, of the total length of the bases (equal to $n \times 244 \cdot 8$ units), $n \times 365$ units will be pushed by expansion westward from the hot hemisphere into the cold; : and $n \times-278$ units eastward. The bases will cover $n \times 1255 \cdot 1$ square units in the hot hemisphere, and $n \times 1242.0$ square units in the cold. Whence by comparing the whole pressures, in respect of the cubes of air in question, upon the bases in each hemisphere we have the mean pressures in the hot and cold hemispheres in the respective ratio of 1.00 to 1.02 . But the mean barometric pressure in the hot hemisphere is 26.1337 inches, and in the cold hemisphere it is 26.153 inches, i.e., in the ratio of 1.000 to 1.001 . The result seems to show that in the given zone the hypothesis that the expansion is equal in all directions would require the transfer of more air into the cold hemisphere than barometric observations warrant.

* Agreeing with the fact that the air-temperature begins to rise before sunrise. The most energetic expansion is in the direction of the primary barometric maximum, the least energetic expansion being towards the secondary maximum. 
The answer is simple. If the units be yards the mean height of each cube would be 10.2 yards, and there would be a measurable difference between the pressure at this height and that at the bottom. Hence the expansion by heating would be easier upwards than outwards. On the other hand, the contraction by cooling would be more energetic inwards near the ground than downwards, resulting in an indraught throughout the whole cool hemisphere, and thereby assisting to some extent the outward expansion opposite. It seems scarcely likely that the excess of upward over outward expansion can extend to the highest limits of the atmosphere, but it is not unlikely that much of it intermixes with the constant northwesterly current above, in the cloud strata, and is thus drawn off as an outflow. If, however, expansion be wholly upwards, and contraction wholly downwards, the base of each cube will at first remain unaltered in size and shape, together with the pressure upon it, the tops of the cubes rising by different amounts, but also remaining in a surface of equal pressure; and no transfer of air can ensue, either above or below, until the high crest of the expanded air falls away from its altitude. Curiously enough, von Siemens maintains that in a surface of equal pressure, such as that in which our expanded and contracted cubes are supposed to lie, there can be no sliding away down the slope of equal pressure by the higher portions. The statement is doubtless only statically true, for it leaves out of account the fact that a free particle on an expanding surface is by the mere acquisition of motion projected by the earth's rotation into an elliptical orbit with a focus at the earth's centre of gravity. Consequently the atmospheric chimney must tend to bend over at the top in the direction of the equator, giving relief to the pressure at its base. The total effect is probably not great, yet it may partially explain the differences in the two calculated results above. On the whole, the case for an actual spiral outflow near the ground, from the hot to the cold hemisphere, seems to be not only possible, but very probable. 
96 Transactrons of the South African Philosophical Society.

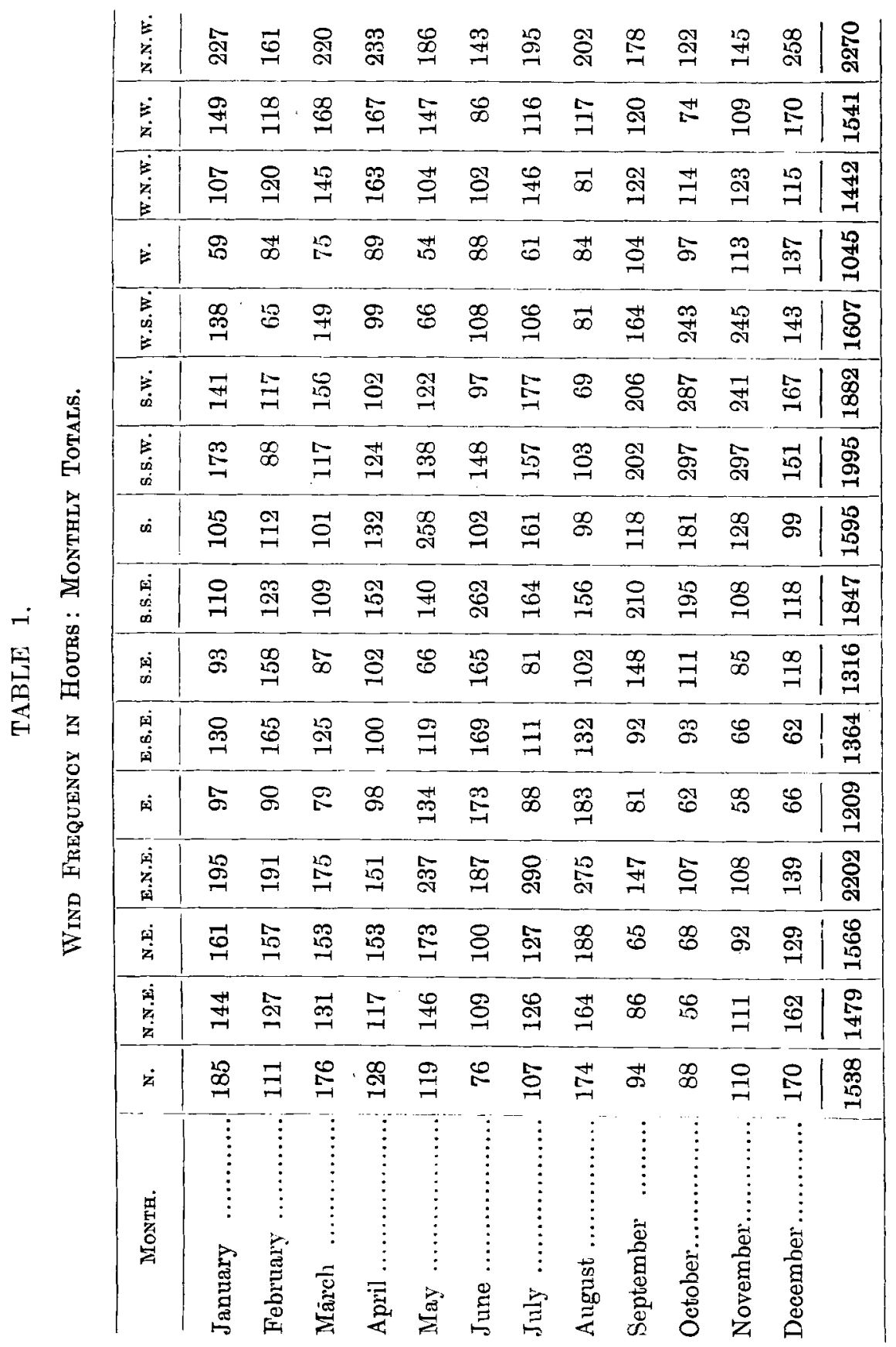


TABLE 2.

Monthly Components of Wind Frequency.

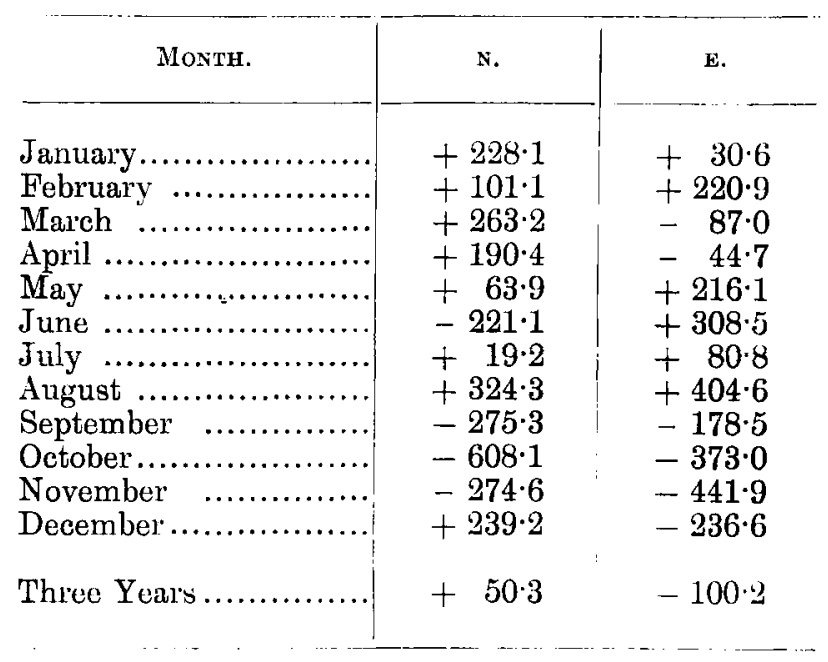

TABLE 3.

Wind Frequency in Hours arranged in Quadiants: Monthly Totals.

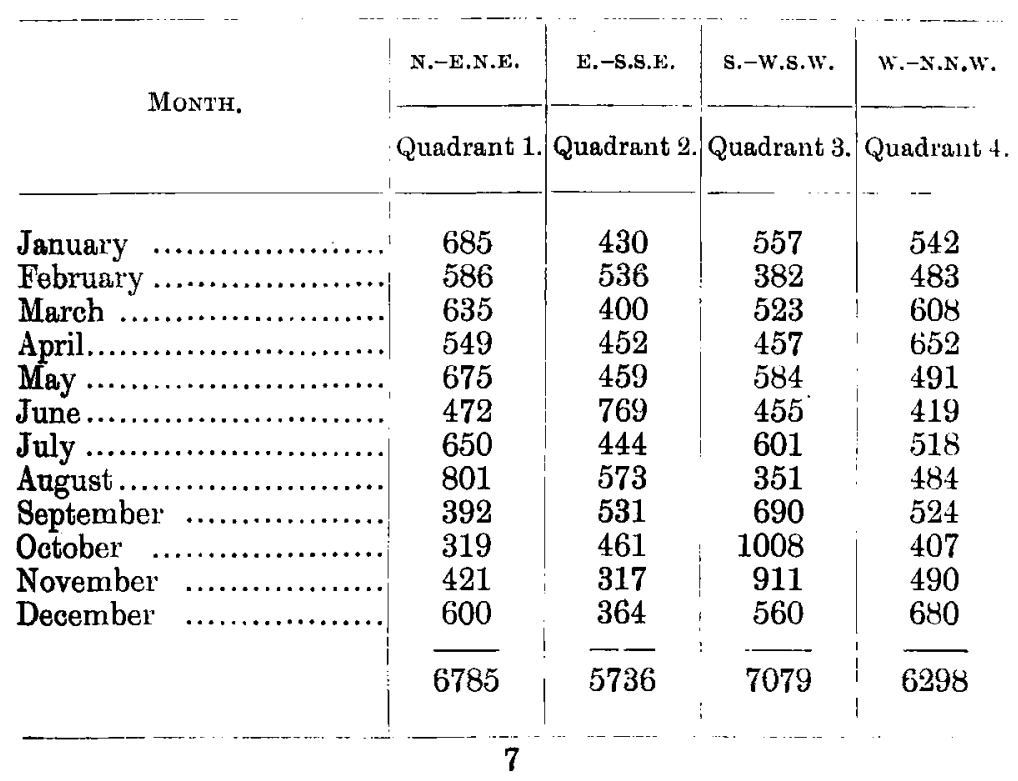


98 Transactions of the South African Philosophical Society.
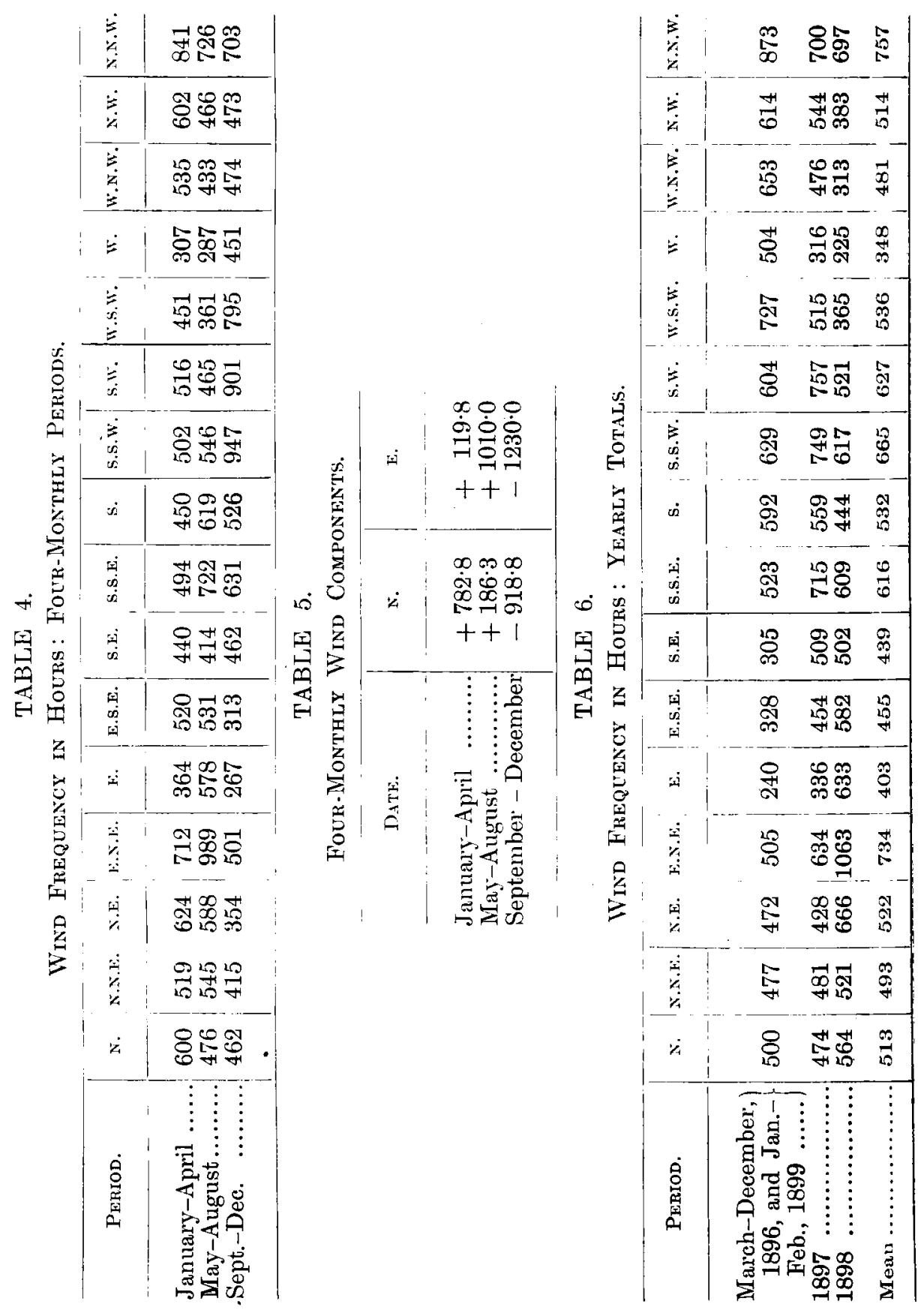


\begin{tabular}{|c|c|c|c|}
\hline & 离 & 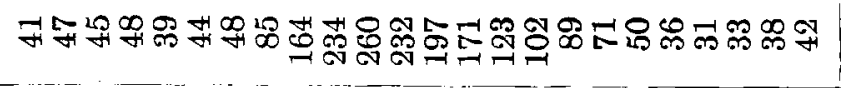 & 玅 \\
\hline & $\dot{s}$ & 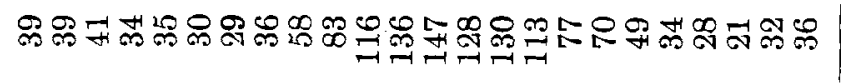 & 10 \\
\hline & $\dot{4}$ & 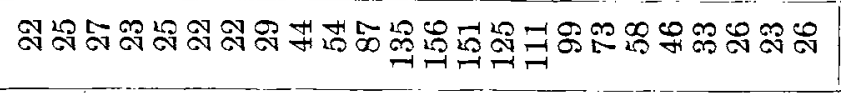 & $\exists$ \\
\hline & $\dot{\vec{z}}$ & 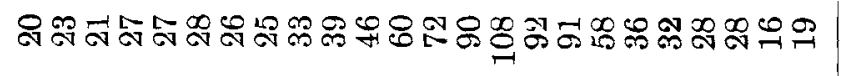 & 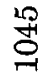 \\
\hline & 离 & 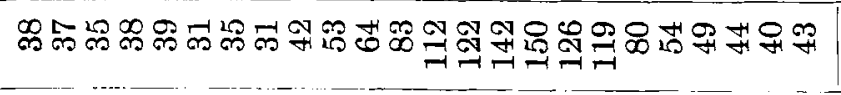 & 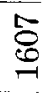 \\
\hline & $\dot{s}$ & 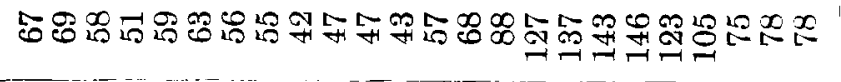 & $\infty$ \\
\hline 象 & 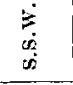 & 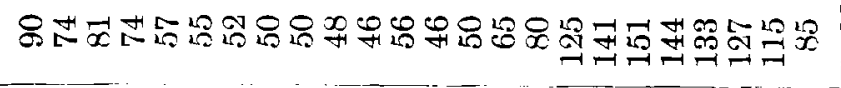 & $\stackrel{\mathscr{S}}{\mathscr{S}}$ \\
\hline$>^{4}$ & $\dot{x}$ & 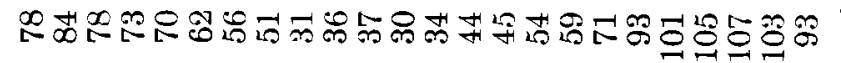 & 㖞 \\
\hline$\therefore \sum^{2}$ & 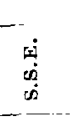 & 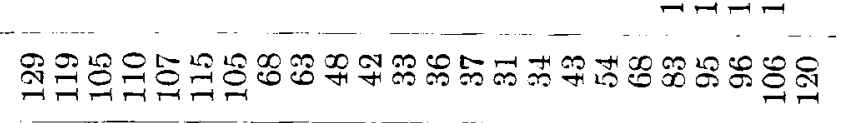 & 点 \\
\hline$\ddot{\ddot{z}}$ & $\dot{s i}$ & 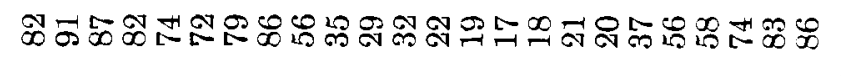 & $\stackrel{\infty}{\infty}$ \\
\hline 甾 & 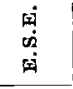 & 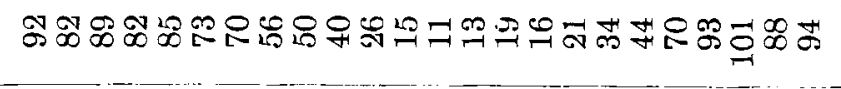 & 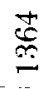 \\
\hline a & $\dot{r}$ & 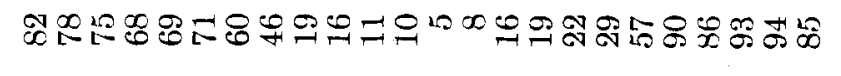 & \& \\
\hline 3 & 艘 & 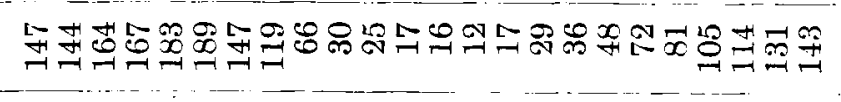 & $\bar{\sigma}$ \\
\hline & 我 & 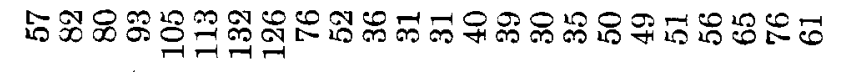 & $\stackrel{\mathscr{E}}{\mathscr{C}}$ \\
\hline & 里 & 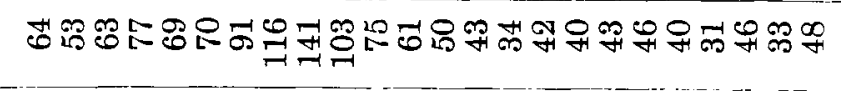 & I \\
\hline & $\dot{A}$ & 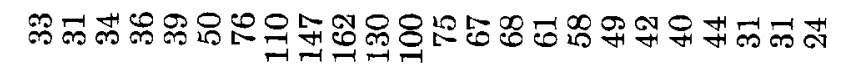 & $\underset{c}{\alpha}$ \\
\hline & 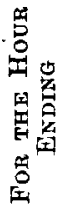 & 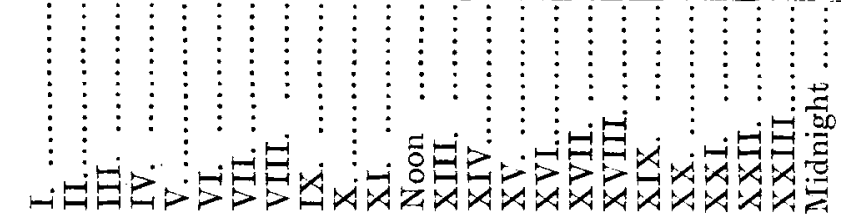 & 元 \\
\hline
\end{tabular}


Transactions of thic South African Philosophical Socicty.

\begin{tabular}{|c|c|c|c|}
\hline & 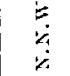 & 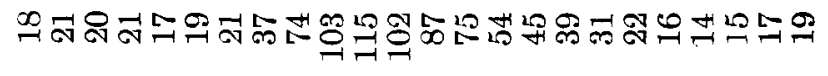 & 串 \\
\hline & $\ddot{\ddot{\ddot{厶}}}$ & 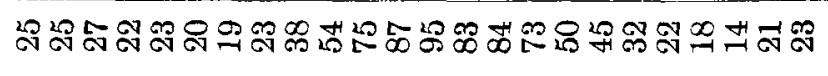 & $\underset{8}{8}$ \\
\hline & $\dot{\bar{\vdots}}$ & 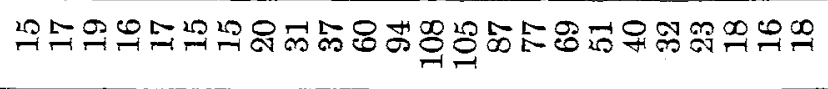 & $\oint_{-1}^{8}$ \\
\hline & $\ddot{\xi}$ & 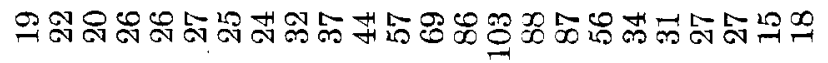 & $\xi$ \\
\hline & $\ddot{\Xi}$ & 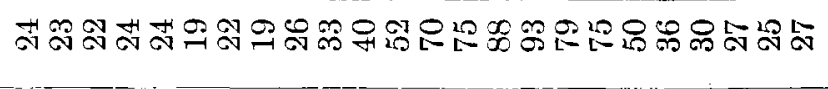 & 8 \\
\hline$\stackrel{1}{\stackrel{9}{E}}$ & $\dot{\vec{C}}$ & 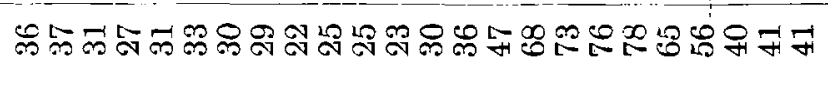 & $\underset{8}{\varnothing}$ \\
\hline$\stackrel{20}{20}$ & 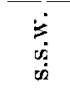 & 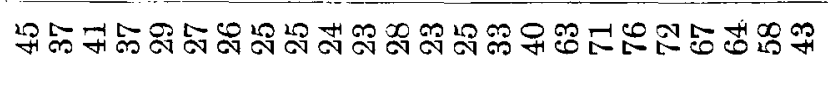 & 8 \\
\hline 要 & $\dot{\phi}$ & 羿 & 8 \\
\hline $\begin{array}{ll}\infty & \bar{\theta} \\
\omega & \ddot{\gamma}\end{array}$ & $\begin{array}{l}\dot{0} \\
\dot{0} \\
\dot{0} \\
\dot{0}\end{array}$ & 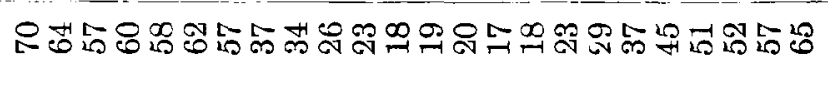 & 8 \\
\hline 畐 & $\dot{m}$ & 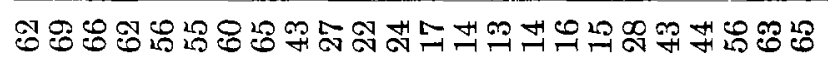 & 8 \\
\hline 蛋 & : & 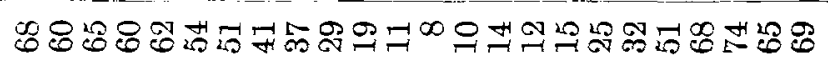 & 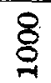 \\
\hline 笲 & $\dot{5}$ & 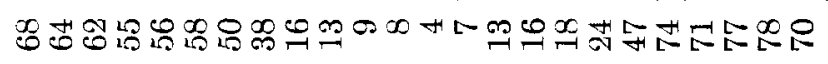 & 8 \\
\hline$\stackrel{5}{5}$ & 艄 & 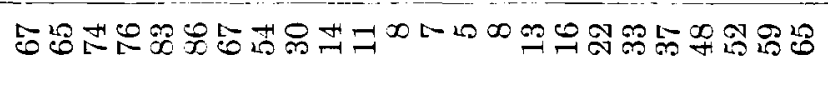 & \&్రి \\
\hline 幽 & ig & 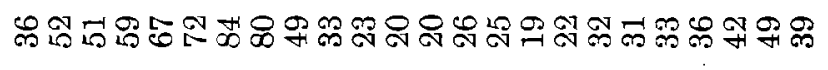 & 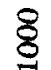 \\
\hline & $\stackrel{4}{4}$ & 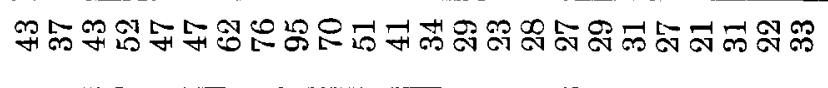 & $\S_{-1}^{-1}$ \\
\hline & 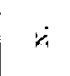 & 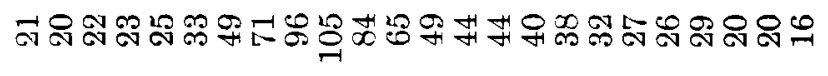 & $\underset{8}{8}$ \\
\hline & 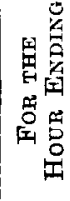 & 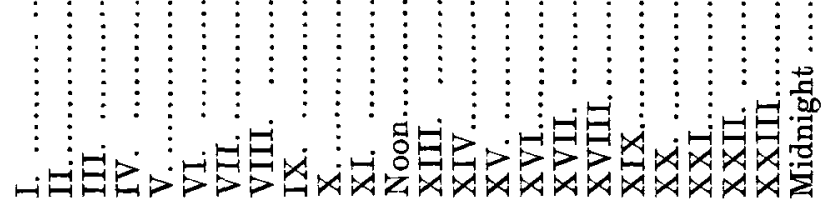 & 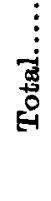 \\
\hline
\end{tabular}


TABLE 9.

Hourly Wind-Frequency Components.

\begin{tabular}{|c|c|c|}
\hline Hour ENDING & N. & $\mathbf{E}$. \\
\hline 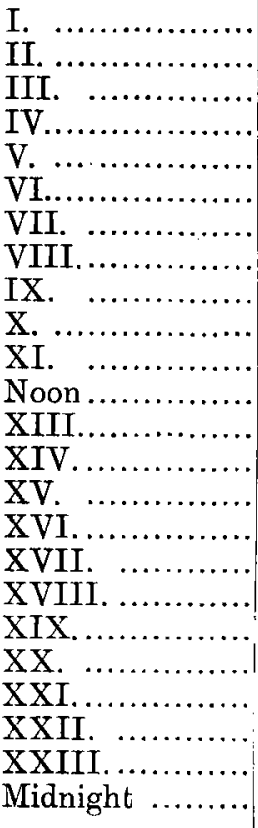 & $\begin{array}{l}-172 \cdot 9 \\
-147 \cdot 4 \\
-107 \cdot 4 \\
-\quad 69 \cdot 0 \\
-\quad 45 \cdot 6 \\
-\quad 17 \cdot 1 \\
+\quad 46 \cdot 2 \\
+173 \cdot 9 \\
+325 \cdot 7 \\
+382 \cdot 7 \\
+383 \cdot 4 \\
+344 \cdot 2 \\
+282 \cdot 2 \\
+208 \cdot 3 \\
+117 \cdot 3 \\
+\quad 23 \cdot 4 \\
-\quad 74 \cdot 1 \\
-139 \cdot 5 \\
-222 \cdot 4 \\
-265 \cdot 8 \\
-271 \cdot 8 \\
-255 \cdot 5 \\
-238 \cdot 1 \\
-210 \cdot 4\end{array}$ & $\begin{array}{l}+274 \cdot 4 \\
+272 \cdot 0 \\
+294 \cdot 6 \\
+303 \cdot 2 \\
+321 \cdot 2 \\
+334 \cdot 1 \\
+307 \cdot 7 \\
+231 \cdot 6 \\
+32 \cdot 5 \\
-137 \cdot 7 \\
-269 \cdot 0 \\
-378 \cdot 1 \\
-456 \cdot 5 \\
-462 \cdot 0 \\
-467 \cdot 0 \\
-448 \cdot 9 \\
-386 \cdot 1 \\
-275 \cdot 8 \\
-109 \cdot 7 \\
+\quad 48 \cdot 0 \\
+137 \cdot 2 \\
+222 \cdot 5 \\
+251 \cdot 4 \\
+260 \cdot 2\end{array}$ \\
\hline Total ......... & $+50 \cdot 3$ & $-100 \cdot 2$ \\
\hline
\end{tabular}

TABLE 10.

Mean Angular Movement of the Vane in Six-Hour Periods.

\begin{tabular}{|c|c|c|c|c|c|}
\hline Monte. & $0 .-\mathrm{VI}$. & VI.-NOON. & NOON-XVIII. & XVIII.-XXIV. & o.-XXIN. \\
\hline 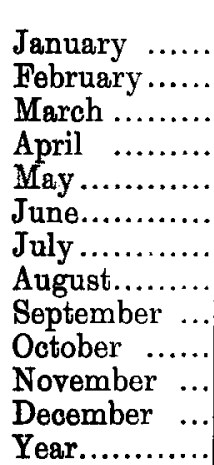 & $\begin{array}{r}\circ \\
+35 \cdot 8 \\
16 \cdot 1 \\
23 \cdot 6 \\
29 \cdot 5 \\
20 \cdot 6 \\
2 \cdot 6 \\
1 \cdot 5 \\
20 \cdot 1 \\
11 \cdot 5 \\
41 \cdot 6 \\
27 \cdot 8 \\
28 \cdot 6 \\
+21 \cdot 6\end{array}$ & $\begin{array}{r}\circ \\
+59 \cdot 7 \\
89 \cdot 2 \\
44 \cdot 3 \\
52 \cdot 7 \\
42 \cdot 7 \\
51 \cdot 3 \\
45 \cdot 8 \\
61 \cdot 0 \\
54 \cdot 1 \\
53 \cdot 3 \\
37 \cdot 7 \\
34 \cdot 6 \\
+52 \cdot 2\end{array}$ & $\begin{array}{r}\text { r } \\
+22 \cdot 4 \\
+27 \cdot 6 \\
+39 \cdot 5 \\
+\quad 8 \cdot 2 \\
+14 \cdot 3 \\
-\quad 5 \cdot 4 \\
+\quad 1 \cdot 0 \\
+11 \cdot 4 \\
-\quad 0.7 \\
+\quad 9 \cdot 4 \\
+11 \cdot 2 \\
+40.6 \\
+14.9\end{array}$ & $\begin{array}{r}\circ \\
+30 \cdot 6 \\
35.8 \\
28.7 \\
13.1 \\
7.9 \\
18.3 \\
13 \cdot 2 \\
15 \cdot 8 \\
26.5 \\
21 \cdot 6 \\
29 \cdot 1 \\
19 \cdot 3 \\
+21.7\end{array}$ & $\begin{array}{r}\circ \\
+148 \cdot 5 \\
168 \cdot 7 \\
136 \cdot 1 \\
103 \cdot 5 \\
85 \cdot 5 \\
66 \cdot 8 \\
61 \cdot 5 \\
108 \cdot 3 \\
91 \cdot 4 \\
125 \cdot 6 \\
105 \cdot 8 \\
123 \cdot 1 \\
+110 \cdot 4\end{array}$ \\
\hline
\end{tabular}


TABLE 11.

A Comparison of the Summer and Winter Values of the Diurnal Variation in Relative Wind Frequency.

QUADRANTS.

\begin{tabular}{|c|c|c|c|c|c|c|c|c|}
\hline \multirow{2}{*}{$\begin{array}{c}\text { FOR THF } \\
\text { HOUR } \\
\text { FNDING }\end{array}$} & \multicolumn{2}{|c|}{$\begin{array}{c}\text { N.-E.N.E. } \\
\text { QUADRANT } 1 .\end{array}$} & \multicolumn{2}{|c|}{$\begin{array}{c}\text { F.-S.S.F. } \\
\text { QUADRANT } 2 .\end{array}$} & \multicolumn{2}{|c|}{$\begin{array}{c}\text { S.-W.S.w. } \\
\text { QLADRANT } 3 .\end{array}$} & \multicolumn{2}{|c|}{$\begin{array}{c}\text { W.-N.N.W. } \\
\text { QUADRANT } 4 .\end{array}$} \\
\hline & Summer. & Winter. & Summer. & Winter. & Summer. & Winter. & Summer. & Winter. \\
\hline I. .. & 46 & 43 & 64 & 66 & 35 & 34 & 31 & 16 \\
\hline II. & 52 & 46 & 66 & 58 & 28 & 36 & 29 & 17 \\
\hline III. . & 51 & 56 & 73 & 51 & 23 & 40 & 29 & 15 \\
\hline IV. & 57 & 53 & 66 & 50 & 24 & 42 & 26 & 18 \\
\hline V.... & 58 & 58 & 66 & 51 & 23 & 36 & 25 & 16 \\
\hline VI. & 62 & 62 & 59 & 50 & 22 & 35 & 29 & 15 \\
\hline VII... & 66 & 58 & 57 & 55 & 23 & 29 & 25 & 20 \\
\hline VIII. .. & 67 & 62 & 44 & 50 & 22 & 31 & 33 & 20 \\
\hline IX. ..... & 55 & 64 & 31 & 35 & 22 & 31 & 55 & 39 \\
\hline $\mathrm{X}$. & 49 & 58 & 25 & 23 & 21 & 33 & 64 & 56 \\
\hline XI. & 37 & 43 & 15 & 18 & 24 & 34 & 79 & 77 \\
\hline Noon & 27 & 28 & 13 & 16 & 30 & 37 & 86 & 97 \\
\hline XIII. & 24 & 25 & 8 & 14 & 38 & 36 & 85 & 101 \\
\hline XIV. & 26 & 23 & 11 & 16 & 45 & 39 & 75 & 100 \\
\hline $\mathrm{XV}$. & 27 & 22 & 15 & 17 & 50 & 47 & 65. & 93 \\
\hline XVI. & 21 & 28 & 14 & 15 & 63 & 59 & 61 & 76 \\
\hline XVII. ... & 21 & 29 & 18 & 19 & 73 & 64 & 52 & 63 \\
\hline XVIII.. & 27 & 34 & 25 & 22 & 78 & 66 & 35 & 46 \\
\hline XIX. & 30 & 36 & 35 & 41 & 78 & 59 & 24 & 28 \\
\hline XX. & 31 & 30 & 49 & 61 & 73 & 50 & 18 & 22 \\
\hline XXI. & 35 & 28 & 60 & 67 & 64 & 46 & 17 & 20 \\
\hline XXII.... & 39 & 35 & 63 & 67 & 56 & 42 & 19 & 18 \\
\hline XXIII... & 47 & 39 & 59 & 69 & 51 & 38 & 16 & 16 \\
\hline Midnight & 48 & 39 & 63 & 68 & 39 & 36 & 23 & 17 \\
\hline
\end{tabular}


The Winds of Kimberley.

103

\begin{tabular}{|c|c|c|c|}
\hline 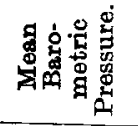 & 总 & 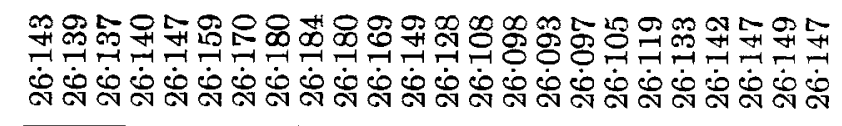 & $\underset{\substack{+\dot{\infty}}}{\dot{\infty}}$ \\
\hline 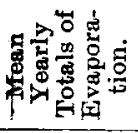 & 总 & 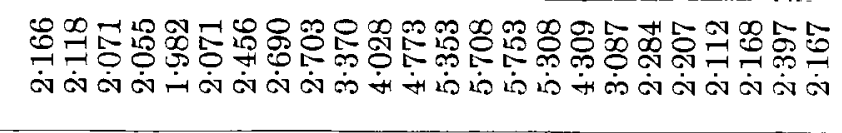 & 8 \\
\hline 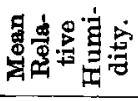 & $\begin{array}{c}\infty \\
\stackrel{\infty}{\infty} \\
\end{array}$ & $\begin{array}{l}0 \\
0 \\
0 \\
0\end{array}$ & 3 \\
\hline \multirow{4}{*}{ 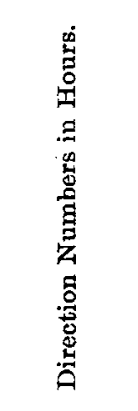 } & \& & 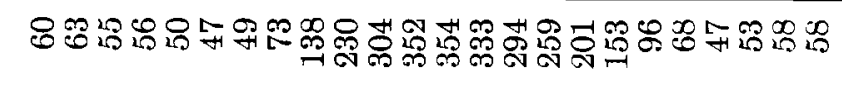 & $\frac{6}{6}$ \\
\hline & 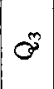 & 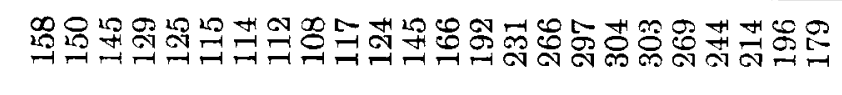 & \\
\hline & a & 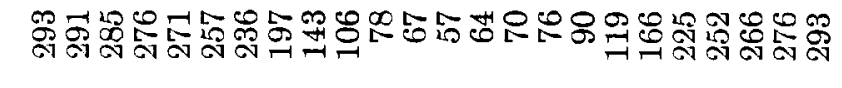 & $\stackrel{4}{\pi}$ \\
\hline & 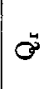 & 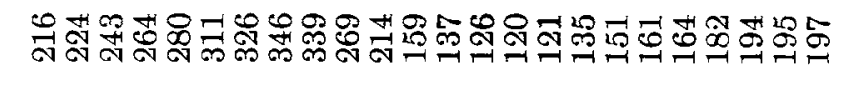 & $\stackrel{4}{5}$ \\
\hline \multirow{4}{*}{ 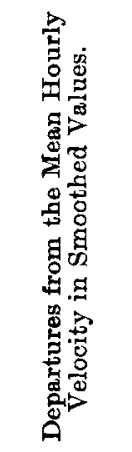 } & $\begin{array}{l}2 \\
1 \\
0 \\
0\end{array}$ & 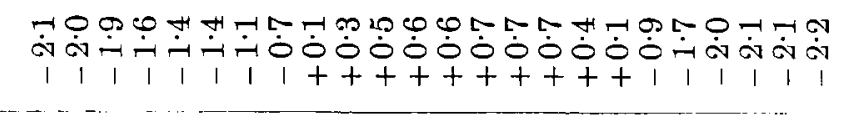 & $\stackrel{9}{\dot{0}}$ \\
\hline & $\mid \begin{array}{l}1 \\
1 \\
0 \\
0\end{array}$ & 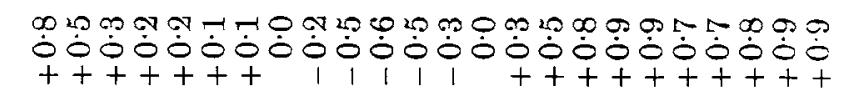 & $\stackrel{\rho}{+}$ \\
\hline & $\mid \begin{array}{l}\sum_{1} \\
\vdots \\
0\end{array}$ & 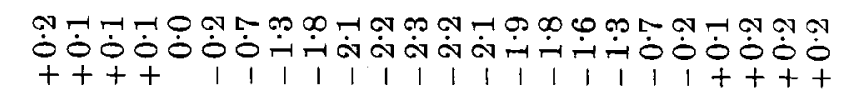 & $\stackrel{P}{+}$ \\
\hline & $\begin{array}{c}7 \\
1 \\
0\end{array}$ & 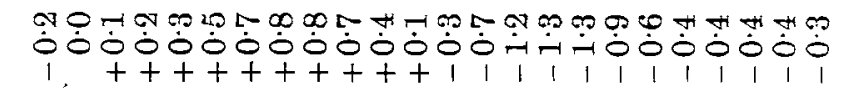 & $\underset{0}{0}$ \\
\hline \multirow{5}{*}{ 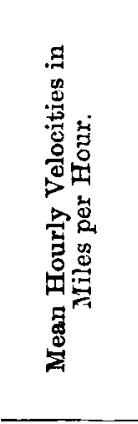 } & $\theta^{*}$ & 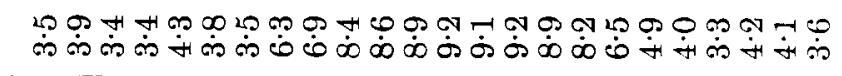 & $?$ \\
\hline & $\infty^{\infty}$ & 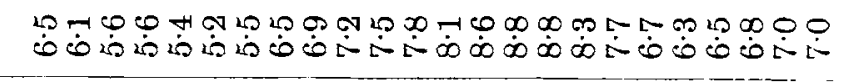 & $\dot{E}$ \\
\hline & $\sigma$ & 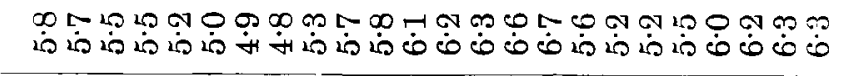 & مُ \\
\hline & $\ddot{\sigma}$ & 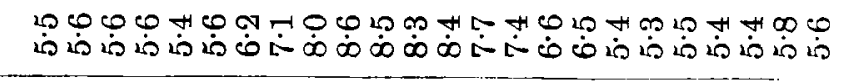 & H \\
\hline & 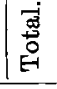 & 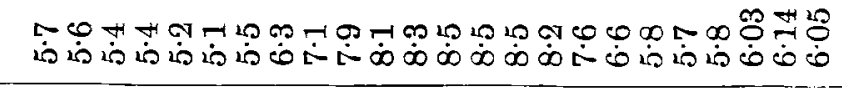 & 0 \\
\hline 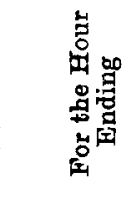 & & 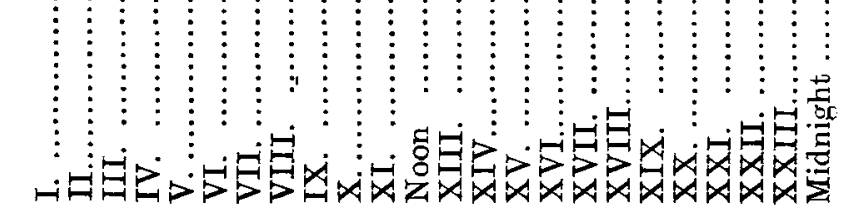 & 家 \\
\hline
\end{tabular}


104 Transactions of the South African Philosophical Society.

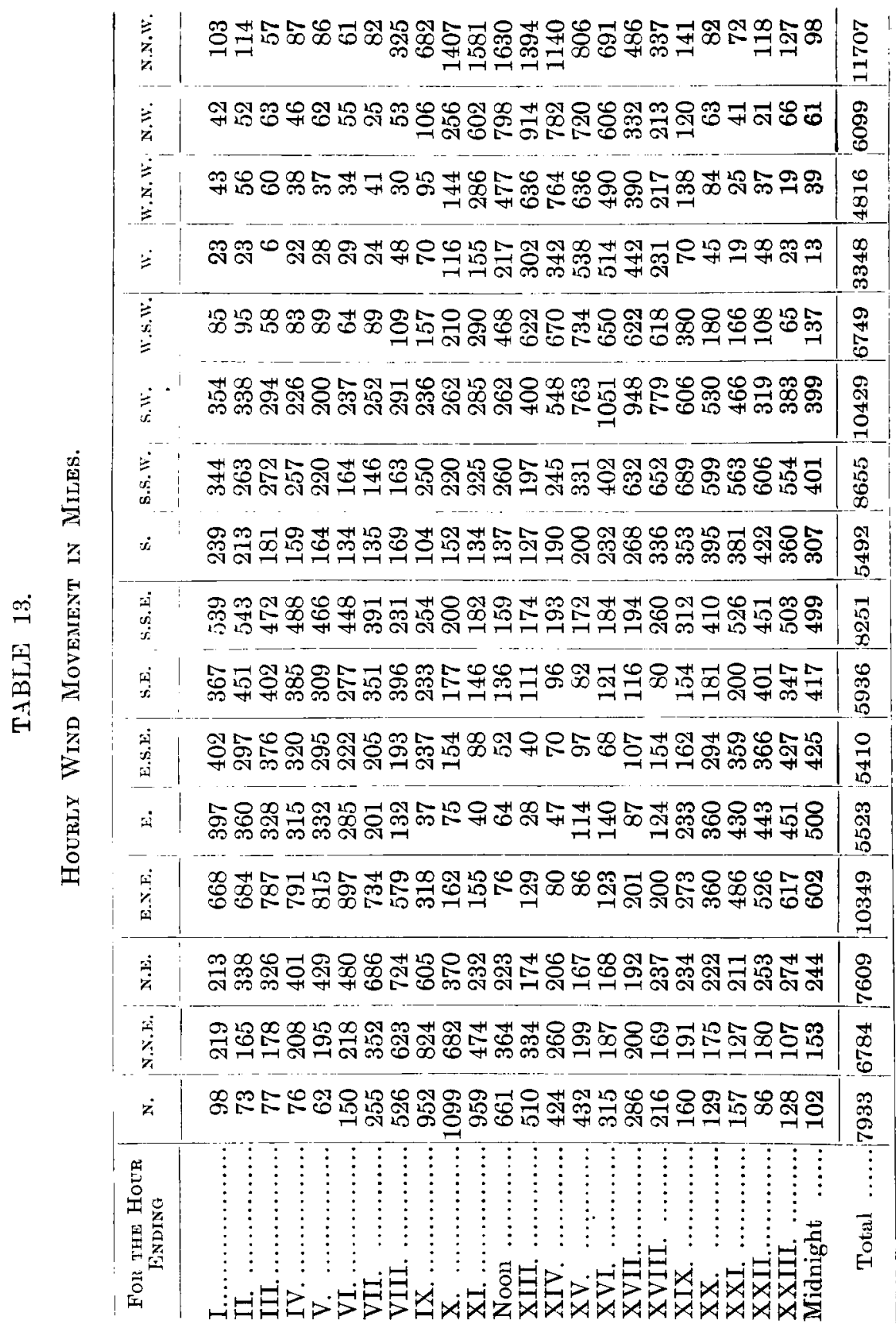


TABLE 14. Hourly Wind-Movenent Componfents.

\begin{tabular}{|c|c|c|}
\hline Hour ENDING & N. & F. \\
\hline I. ........... & $-\quad 903 \cdot 1$ & $+1493 \cdot 4$ \\
\hline II. $\ldots$ & $-775 \cdot 8$ & +15126 \\
\hline III. ... & $-633 \cdot 3$ & $+1672 \cdot 6$ \\
\hline IV. ..... & $-451 \cdot 7$ & $+1705 \cdot 8$ \\
\hline V....... & $-\quad 309 \cdot 8$ & $+1685 \cdot 5$ \\
\hline VI. ...... & $-\quad 30 \cdot 0$ & $+1696 \cdot 8$ \\
\hline VII.... & $+285 \cdot 3$ & $+1658 \cdot 9$ \\
\hline VIII. & $+1050 \cdot 0$ & $+1357 \cdot 6$ \\
\hline IX, ... & $+1952 \cdot 1$ & +653.5 \\
\hline $\mathrm{X} . \quad \ldots$ & $+2599 \cdot 0$ & $-\quad 340 \cdot 7$ \\
\hline XI. ......... & $+2656 \cdot 6$ & $-1222 \cdot 6$ \\
\hline Noon............. & $+2432 \cdot 3$ & $-1926 \cdot 6$ \\
\hline XIII. ............... & $+2084 \cdot 1$ & $-2422 \cdot 2$ \\
\hline XIV. $\ldots \ldots \ldots \ldots \ldots$ & $+1405 \cdot 8$ & $-2564 \cdot 9$ \\
\hline $\mathrm{XV}, \ldots$ & +683.8 & $-2686 \cdot 4$ \\
\hline XVI. $\ldots$ & $+\quad 31 \cdot 2$ & $-2494 \cdot 4$ \\
\hline XVII. .. & $-546 \cdot 0$ & $-1969 \cdot 8$ \\
\hline XVIII. . & $-920 \cdot 2$ & $-1243 \cdot 0$ \\
\hline XIX. ....... & $-1148 \cdot 3$ & $-\quad 277 \cdot 8$ \\
\hline $\mathrm{XX} \ldots \ldots$ & $-1273 \cdot 5$ & $+504 \cdot 2$ \\
\hline XXI. & $-1344 \cdot 4$ & $+954 \cdot 2$ \\
\hline XXII...... & $-1318 \cdot 5$ & $+1271 \cdot 6$ \\
\hline XXIII. & $-1213 \cdot 0$ & $+1409 \cdot 4$ \\
\hline Midnight... & $-1135 \cdot 7$ & $+1473 \cdot 9$ \\
\hline Total & +3176.9 & $+1903 \cdot 6$ \\
\hline
\end{tabular}


106 Transactions of the South African Philosophical Society.

TABLE 15.

Component Variations from a Wind-System of Constant

VeLocity.

\begin{tabular}{|c|c|c|c|c|c|c|c|}
\hline \multirow{2}{*}{$\begin{array}{c}\text { For THE } \\
\text { HoUR } \\
\text { ENDING }\end{array}$} & \multicolumn{3}{|c|}{ Nonth. } & \multicolumn{3}{|c|}{ EAST. } & \multirow[b]{2}{*}{$\begin{array}{c}\text { Resultant } \\
\text { R }\end{array}$} \\
\hline & $\begin{array}{c}\text { Variable } \\
\text { Movenent. } \\
v\end{array}$ & \begin{tabular}{|c|} 
Constant \\
Velocity. \\
c
\end{tabular} & $\begin{array}{c}\text { Difference. } \\
\mathrm{v}-\mathrm{C}\end{array}$ & $\begin{array}{c}\text { Variable } \\
\text { Movement. } \\
\mathrm{v}\end{array}$ & $\begin{array}{c}\text { Constant } \\
\text { Velocity. } \\
\text { c }\end{array}$ & $\begin{array}{c}\text { Difference. } \\
\mathbf{v}-\mathbf{c}\end{array}$ & \\
\hline I. ..... & -452 & -379 & -73 & +747 & +604 & +143 & 161 \\
\hline II. $\ldots$ & -388 & -324 & -64 & +756 & +598 & +158 & 170 \\
\hline III. .... & -317 & -236 & -81 & +836 & +648 & +188 & 243 \\
\hline IV. .... & -226 & -142 & -84 & +853 & +667 & +186 & 238 \\
\hline V...... & -155 & -101 & -54 & +843 & +707 & +136 & 146 \\
\hline VI. & $-\quad 15$ & -38 & +23 & +848 & +735 & +113 & 115 \\
\hline VII... & +143 & +102 & +41 & +829 & +677 & +152 & 157 \\
\hline VIII. & +525 & +383 & +142 & +679 & +510 & +169 & 221 \\
\hline IX. .. & +976 & +717 & +259 & +327 & +72 & +255 & 363 \\
\hline $\mathrm{x} \ldots \ldots$ & +1300 & +842 & +458 & -170 & -303 & +133 & 477 \\
\hline XI. & +1328 & +844 & +484 & -611 & -592 & -19 & 484 \\
\hline Noon & +1216 & +757 & +459 & -913 & -832 & -81 & 466 \\
\hline XIII. & +1042 & +621 & +421 & -1211 & -1004 & -207 & 468 \\
\hline XIV. & +703 & +458 & +245 & -1282 & -1016 & -266 & 361 \\
\hline XV.... & +342 & +258 & +84 & -1343 & -1027 & -316 & 327 \\
\hline XVI. & +16 & +51 & -35 & -1247 & -988 & -259 & 261 \\
\hline XVII. & -273 & -163 & -110 & -985 & -849 & -136 & 175 \\
\hline XVIII.. & -460 & -307 & -153 & - 621 & -607 & -14 & 154 \\
\hline XIX. & -574 & -489 & -85 & -139 & -241 & -102 & 133 \\
\hline $\mathrm{XX} \ldots \ldots$ & -637 & -585 & -52 & +252 & +106 & +146 & 147 \\
\hline XXI. ... & -672 & -598 & -74 & +477 & +302 & +175 & 190 \\
\hline XXII.... & - 659 & -562 & -97 & +636 & +490 & +146 & 173 \\
\hline XXIII... & -607 & -524 & -83 & +705 & +553 & +152 & 152 \\
\hline Midnight & $t-568$ & -462 & -106 & +737 & +572 & +165 & 196 \\
\hline
\end{tabular}


The Winds of Kimberley.

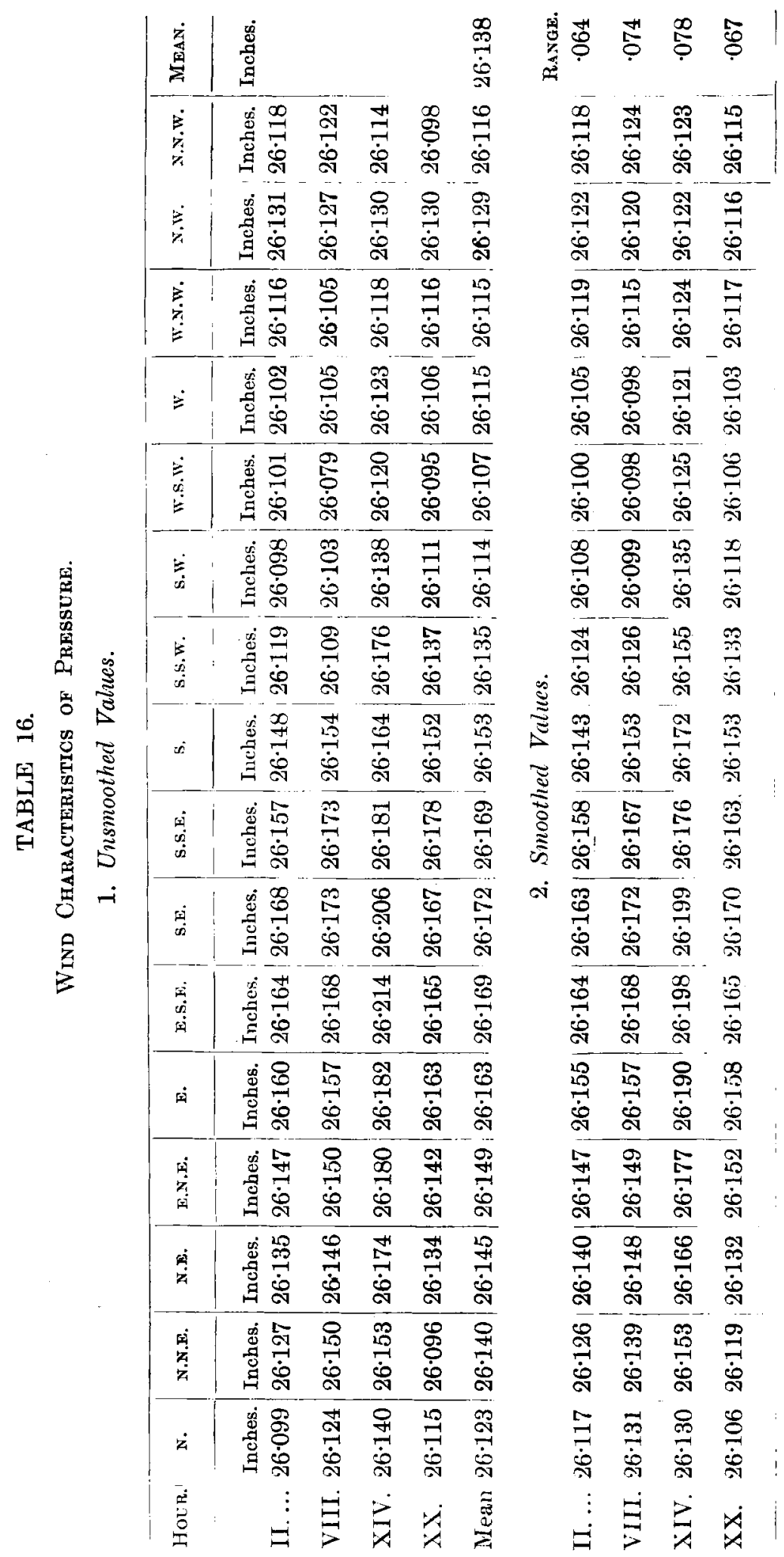




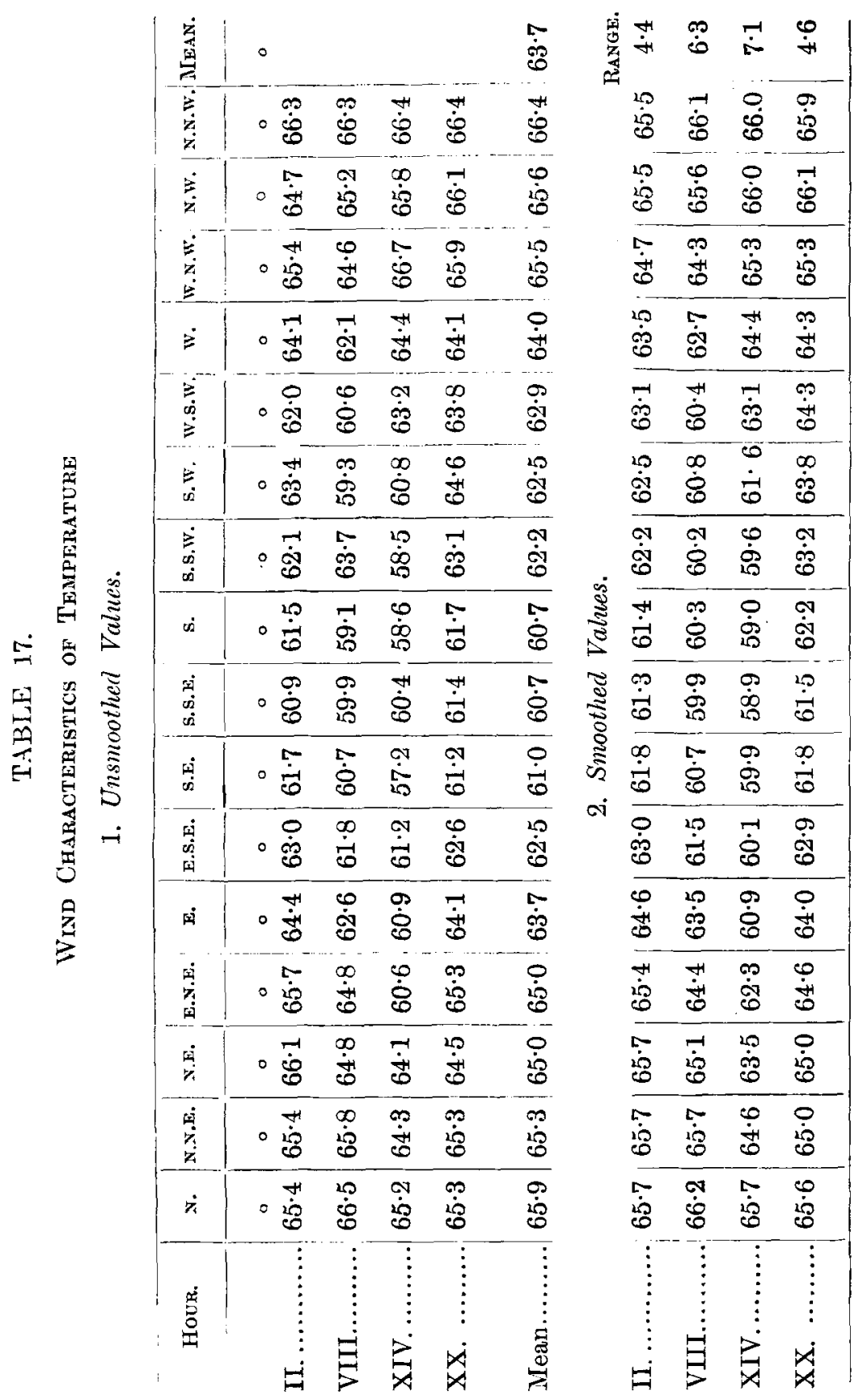


The Winds of Kimberley.

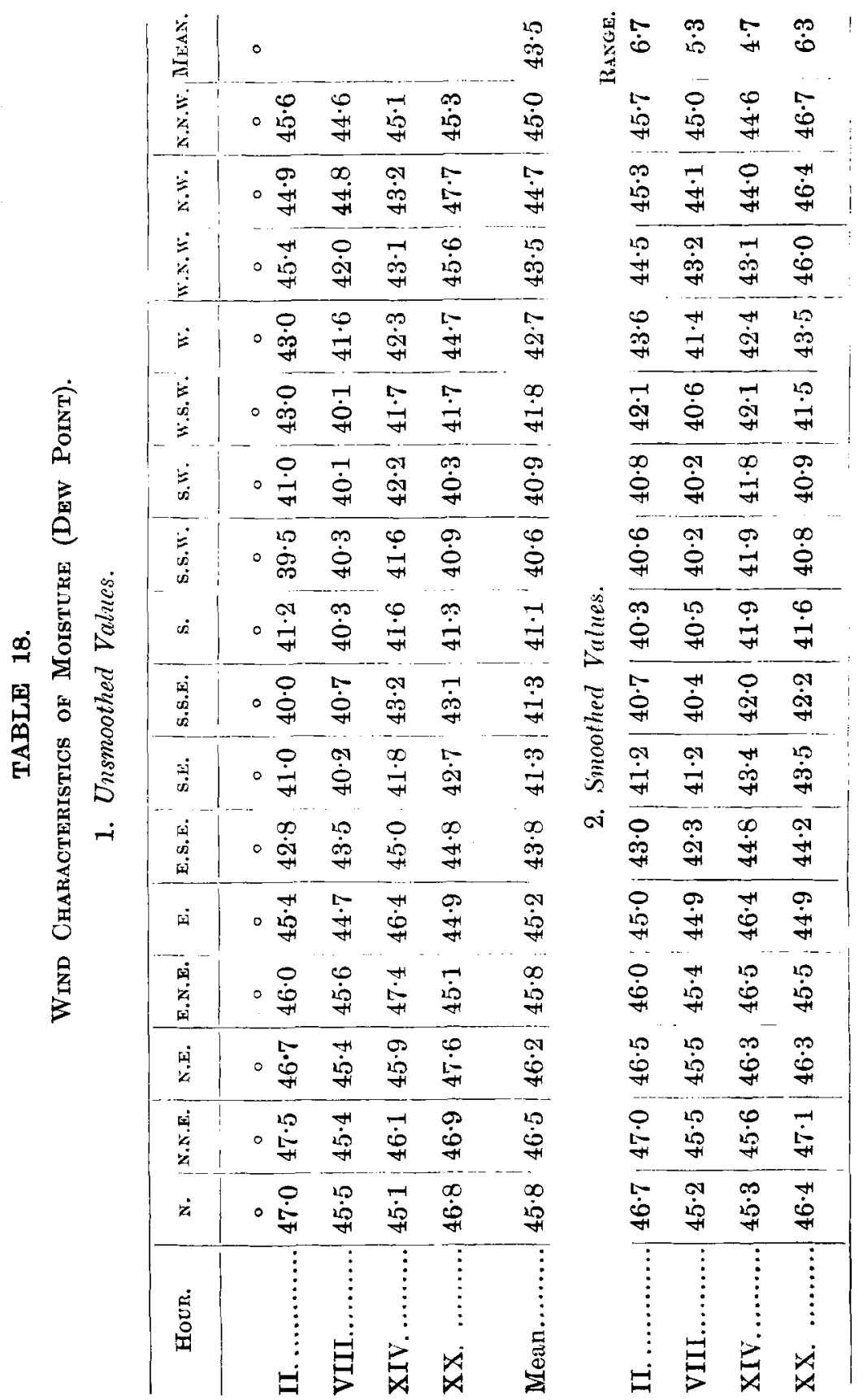


110 Transactions of the South African Philosophical Society.

\begin{tabular}{|c|c|c|c|c|c|c|c|c|c|}
\hline & & 宾 & 穴的灾 & $\underset{\sigma}{\sigma}$ & & & & & $\begin{array}{l}0200 \\
0 \dot{0} 0 \\
1+1\end{array}$ \\
\hline & & 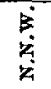 & 它 & ம் & & 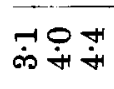 & $\tilde{\dot{\omega}}$ & & $\begin{array}{l}\text { फ05 } \\
\dot{0} \dot{0} \dot{0} \\
1++\end{array}$ \\
\hline & & $\dot{\bar{z}}$ & نூ & $\tilde{\omega}$ & & 我舟 & $\dot{\varphi}$ & & $\begin{array}{l}\dot{0} \\
\dot{0} \dot{0} \dot{0} \\
1++\end{array}$ \\
\hline & & 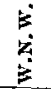 & 官 & $\stackrel{20}{\dot{\infty}}$ & & 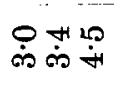 & $\dot{n}$ & & $\begin{array}{l}20 \dot{0} \\
\dot{0} \dot{0} \dot{+1} \\
11+\end{array}$ \\
\hline & & $\ddot{\Xi}$ & 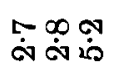 & के & & 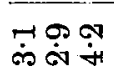 & $\begin{array}{l}\text { co } \\
\dot{\text { is }}\end{array}$ & & 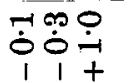 \\
\hline & & 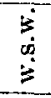 & $\begin{array}{l}10+1 \\
\dot{\sigma} \dot{\sigma}\end{array}$ & $\underset{\dot{\sigma}}{\dot{\sigma}}$ & & $\dot{\phi} \dot{\infty} \dot{\infty}$ & $\stackrel{\leftrightarrow}{\dot{\alpha}}$ & & $\begin{array}{l}+\dot{0}+\overrightarrow{0} \\
+1+\end{array}$ \\
\hline & & $\underset{\dot{B}}{\dot{B}}$ & 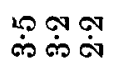 & $\stackrel{\infty}{\dot{\sigma}}$ & & $\dot{\infty} \dot{\infty} \dot{\sigma}$ & ڤે & & $\begin{array}{l}x \\
\dot{0} \dot{0} \dot{0} \\
++1\end{array}$ \\
\hline 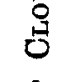 & & $\begin{array}{l}\dot{B} \\
\dot{c o} \\
\dot{0}\end{array}$ & ஸे & 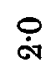 & & 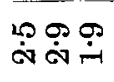 & $\dot{\sigma}$ & జే & $\begin{array}{l}9 \varphi \\
0 \dot{0} \dot{0} \\
++1\end{array}$ \\
\hline & $\frac{\pi}{8}$ & $\dot{\Delta}$ & में & $\stackrel{\sigma}{\dot{\rho}}$ & 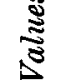 & $\stackrel{+}{\dot{\sim}} \dot{\sim}$ & $\stackrel{\circ}{\dot{\omega}}$ & $\$$ & ஜ் \\
\hline 易 & $\frac{\mathbb{\Xi}}{8}$ & $\dot{d}$ & 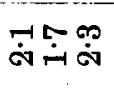 & $\vec{\sigma}$ & జ్తు & 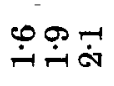 & $\stackrel{\varphi}{\dot{\sim}}$ & : & mín \\
\hline 这 & 衰 & $\dot{s}$ & مِ & $\stackrel{\varphi}{-1}$ & ऊँ̃ & & $\vec{\theta}$ &. & சिं \\
\hline & - & 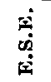 & में क्ष & $\stackrel{20}{\dot{\sigma}}$ & ov & $\begin{array}{l}\dot{\sigma} \dot{\sigma} \dot{\sigma} \\
\dot{\sigma}\end{array}$ & $\dot{\sigma o g}$ & $\tilde{\widetilde{\Xi}}$ & मधि \\
\hline$\rightarrow$ & & $\dot{s}$ & 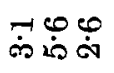 & $\dot{\sim}$ & & 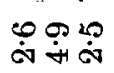 & $\stackrel{\leftrightarrow}{\dot{\sigma}}$ & & mó \\
\hline & & 案 & هั & $\underset{\dot{\alpha}}{\sigma}$ & & 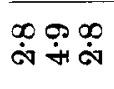 & ஜ่ & & $\begin{array}{l}0 \\
\dot{0} \\
\dot{1}+\dot{0}\end{array}$ \\
\hline & & 迹 & $\begin{array}{l}\infty \\
\dot{\omega}\end{array}$ & $\ddot{m}$ & & ஸे & $\stackrel{\oplus}{\dot{\infty}}$ & & $\begin{array}{l}200 \\
09 \dot{0} \\
1+\end{array}$ \\
\hline & & 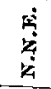 & $\dot{\sim} \dot{\vec{\sigma}} \dot{\omega}$ & $\ddot{m}$ & & 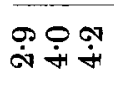 & $\stackrel{H}{H}$ & & $\begin{array}{l}1000 \\
0 \dot{0} 0 \\
1++\end{array}$ \\
\hline & & $\dot{\vec{z}}$ & 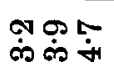 & $\dot{\varphi}$ & & مُ & $\leftarrow$ & & $\begin{array}{l}\infty \infty \\
0 \dot{0} \dot{0}\end{array}$ \\
\hline & & 嗾 & $\begin{array}{c}\vdots \\
\vdots \\
\vdots \\
\beta\end{array}$ & : & & 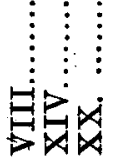 & 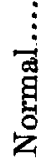 & & 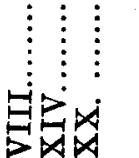 \\
\hline
\end{tabular}


TABLE 20.

Variations of Cubic Volumes of Atr with Temperature.

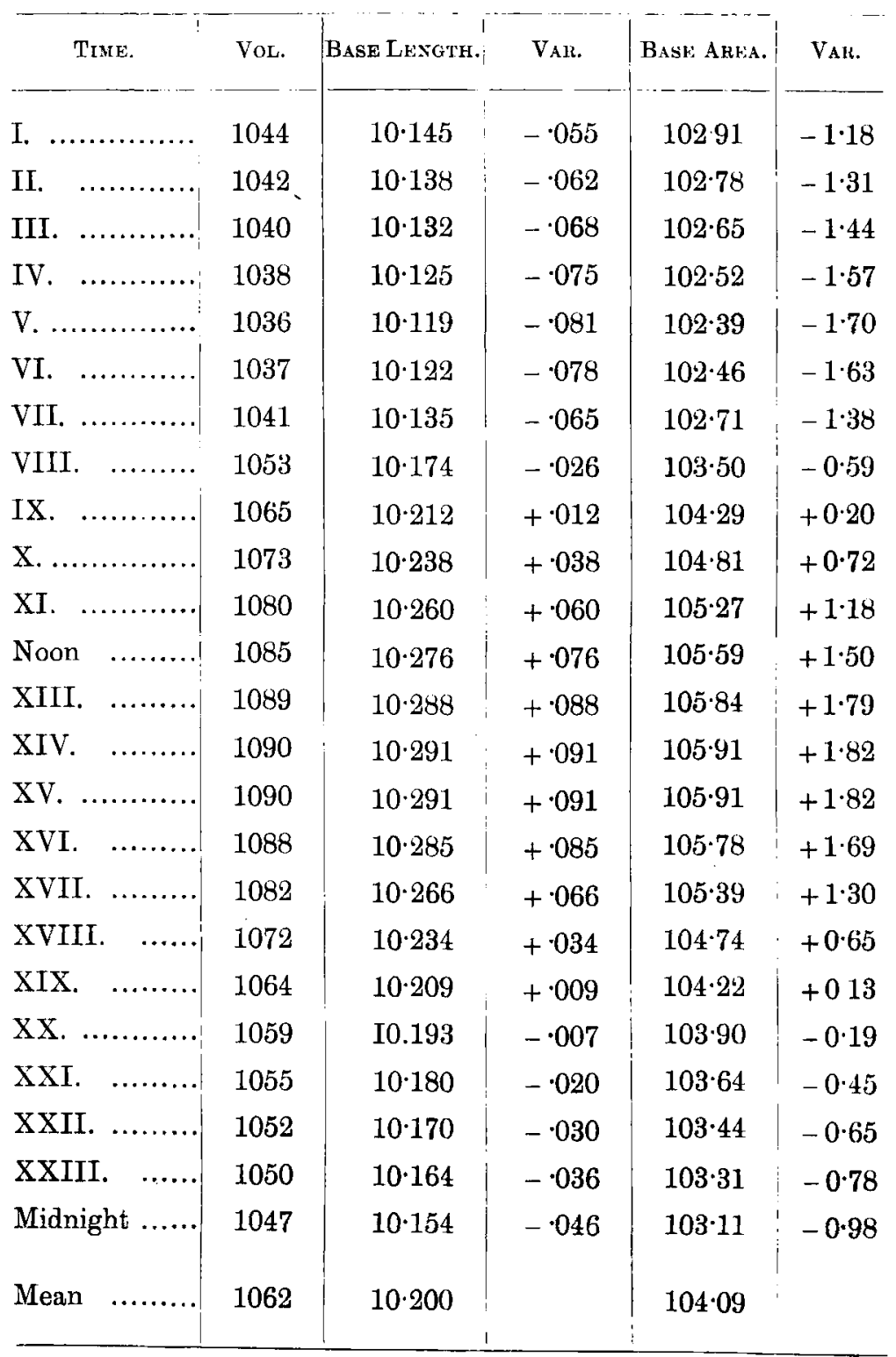


112 Transactions of the South African Philosophical Society.

\section{PLA'TES II. 'T'O IX.}

Plate II. Fig. 1. Monthly Wind-Frequency Resultants.

" III. , 2. Wind-Frequency.

" IV. , 3. Wind-Frequency Components.

" V. " 4. Wind-Frequency Resultants.

"VI. , 5. Variation of Wind Velocity from the Normal Curve.

" VII. " 6 . Wind-Movement Components.

" VIII. ", 7. Wind-Variation Components.

"IX. " 8 . Wind Scheme. 